\title{
Innovative Comparison of Transient Ignition Temperature at the Booster Interface, New Stainless Steel Pyrovalve Primer Chamber Assembly " $V$ " (PCA) Design versus the Current Aluminum “Y” PCA Design
}

\author{
Regor L. Saulsberry ${ }^{1}$ \\ NASA Johnson Space Center White Sands Test Facility, Las Cruces, New Mexico 88004 \\ Stephen H. McDougle ${ }^{2}$ \\ NASA Test and Evaluation Contract, NASA Johnson Space Center White Sands Test Facility, \\ Las Cruces, New Mexico 88004 \\ and \\ Roberto Garcia ${ }^{3}$ and Kenneth L. Johnson ${ }^{4}$ \\ NASA Marshall Space Flight Center \\ Huntsville, Alabama 35811 \\ William Sipes ${ }^{5}$ \\ Canyon Country, California 91351 \\ Steven Rickman ${ }^{6}$ \\ NASA Johnson Space Center \\ Houston, Texas 77058 \\ Ashvin Hosangadi ${ }^{7}$ \\ Combustion Research and Flow Technology, Inc (Craftech) \\ Pipersville, Pennsylvania 18947
}

\begin{abstract}
An assessment of four spacecraft pyrovalve anomalies that occurred during ground testing was conducted by the NASA Engineering \& Safety Center (NESC) in 2008. In all four cases, a common aluminum (Al) primer chamber assembly (PCA) was used with dual NASA Standard Initiators (NSIs) and the nearly simultaneous (separated by less than 80 microseconds $(\mu \mathrm{s})$ ) firing of both initiators failed to ignite the booster charge. The results of the assessment and associated test program were reported in AIAA Paper AIAA-2008-4798, NESC Independent Assessment of Pyrovalve Ground Test Anomalies.

As a result of the four Al PCA anomalies, and the test results and findings of the NESC assessment, the Mars Science Laboratory (MSL) project team decided to make changes to the PCA. The material for the PCA body was changed from aluminum (Al) to stainless steel (SS) to avoid melting, distortion, and potential leakage of the NSI flow passages when the device functioned. The flow passages, which were interconnected in a Y-shaped configuration (Y-PCA) in the original design, were changed to a V-shaped configuration
\end{abstract}

1 Project Manager, Laboratories Office/RF, P.O. Box 20, Las Cruces, New Mexico 88004, Senior Member.

2 Senior Project Engineer, Laboratories Department/201LD, P.O. Box 20, Las Cruces, New Mexico 88004, Associate Fellow.

3 NESC Assessment Requestor, NASA Propulsion Fellow, NESC Propulsion Technical Discipline Team Lead, Huntsville, Alabama 35811.

4 AST, Technical Management, Statistics and Trending, NESC Systems Engineering Organization, Bldg 4201, Rm. 419, Huntsville, Alabama 35811.

5 Pyrotechnic Consultant, 18850 Laurel Crest Lane, Canyon Country, California 91351.

6 NASA Technical Fellow for Passive Thermal, NESC, 2101 NASA Parkway, Houston, Texas 77058.

7 Principal Scientist, 6210 Keller’s Church Road, Pipersville, Pennsylvania 18947. 
(V-PCA). The V-shape was used to more efficiently transfer energy from the NSIs to the booster. Development and qualification testing of the new design clearly demonstrated faster booster ignition times compared to the legacy AL Y-PCA design. However, the final NESC assessment report recommended that the SS V-PCA be experimentally characterized and quantitatively compared to the Al Y-PCA design. This data was deemed important for properly evaluating the design options for future NASA projects. This test program has successfully quantified the improvement of the SS V-PCA over the Al Y-PCA. A phase B of the project was also conducted and evaluated the effect of firing command skew and enlargement of flame channels to further assist spacecraft applications.

\section{Nomenclature}

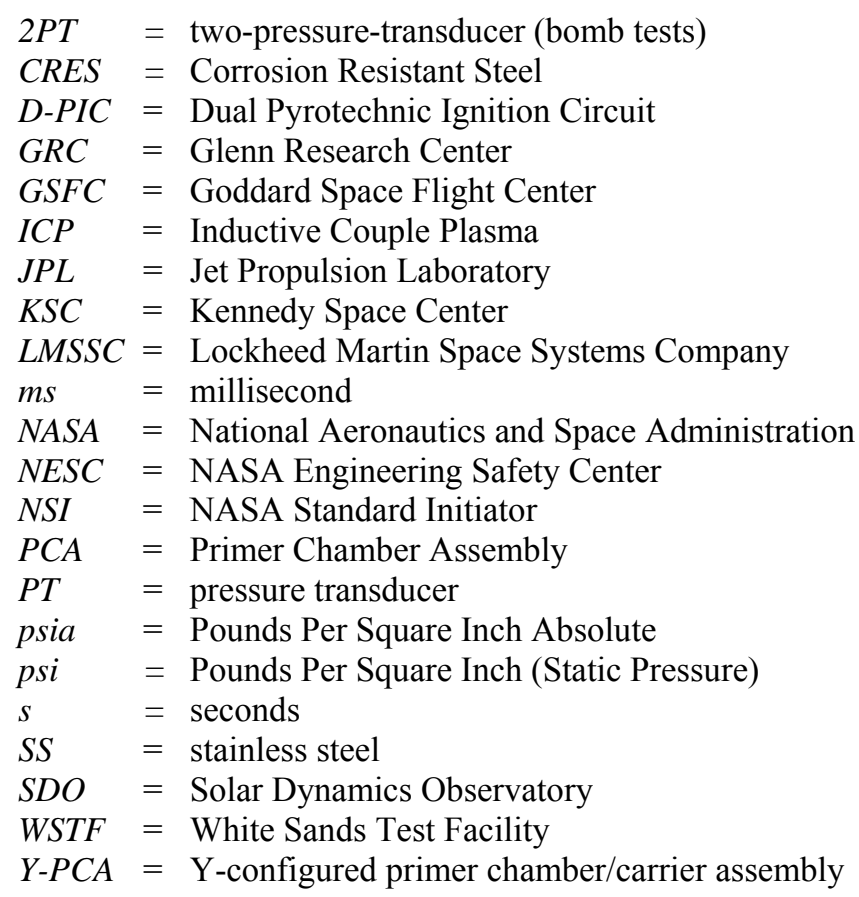

\section{Introduction}

IN October 2008, the NASA Engineering and Safety Center (NESC) generated a report entitled, Conax Y-PCA (Primer Chamber Assembly) Booster Anomaly Investigation. ${ }^{1}$ The report detailed an independent assessment of four spacecraft propulsion system pyrovalve anomalies that occurred during ground testing. In all four cases, a common aluminum (Al) PCA featuring dual NASA Standard Initiators (NSI) was used. In the ground tests, the nearly simultaneous (separated by less than 80 microseconds $(\mu \mathrm{s})$ ) firing of both initiators failed to ignite the booster charge.

As a result of the NESC's assessment work and because the Mars Science Laboratory (MSL) spacecraft planned to use pyrovalves with similar features, the MSL project team decided to make modifications to the PCA to avoid potential anomalies. Two modifications were made. The material for the PCA body was changed from Al to stainless steel (SS) to avoid melting and distortion of the NSI flow passages when the device functioned. Secondly, the interconnected flow passages were separated. Instead of a Y-shape configuration, a V-shape was used to more efficiently transfer energy from the NSIs to the booster charge (Fig. 1). Development and qualification testing of the new design clearly demonstrated improved performance in terms of shorter booster ignition times and greater margin for booster ignition.

However, the final NESC report of the ground test anomalies recommended that the SS V-PCA should be experimentally characterized and quantitatively compared to the Al Y-PCA design prior to widespread application in NASA programs. In addition to benefitting MSL as originally planned, this data would provide future NASA projects with information necessary to properly evaluate the selection and use of the SS V-PCA versus the Al YPCA. This assessment implements that recommendation. 


\section{Testing Test Apparatus}

All phases of the test project, and both the Al Y-PCA and SS V-PCA test articles, used a sapphire window arrangement in the booster location (Fig. 1). The Al Y-PCA test article consisted of a sealing ring, a booster cover simulator (0.003-in. thick SS membrane), the sapphire window, and a spacer ring (Fig. 2). The parts were held in place by a retaining nut on the bottom of the PCA.

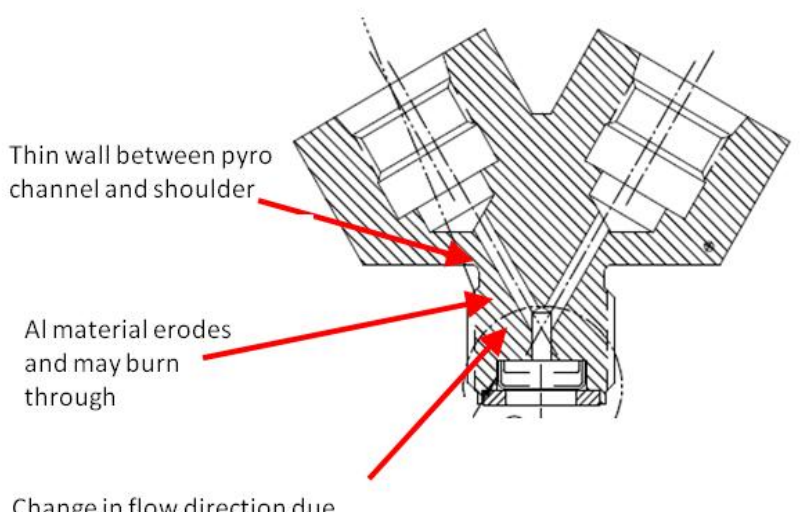

Change in flow direction due to $\mathrm{Y}$-configuration may compromise ignition
HERITAGE

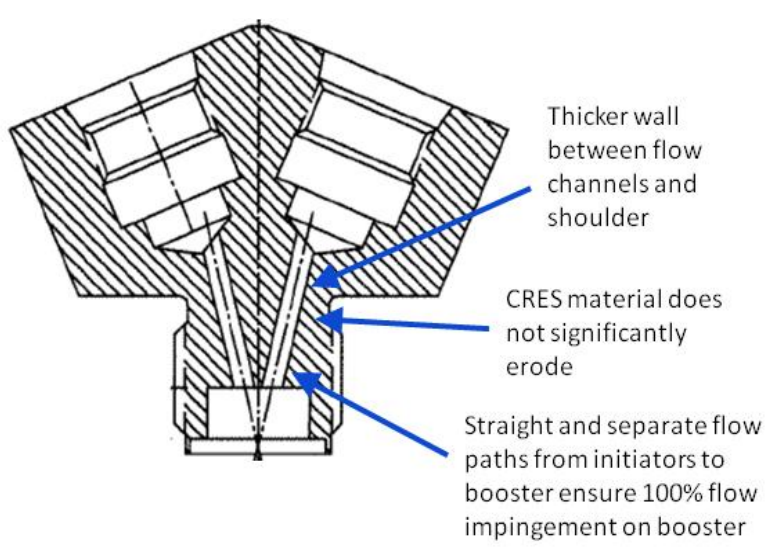

MSL: CRES-V

Figure 1. Comparison of Al Y-PCA (Heritage) to SS V-PCA (MSL: CRES-V).

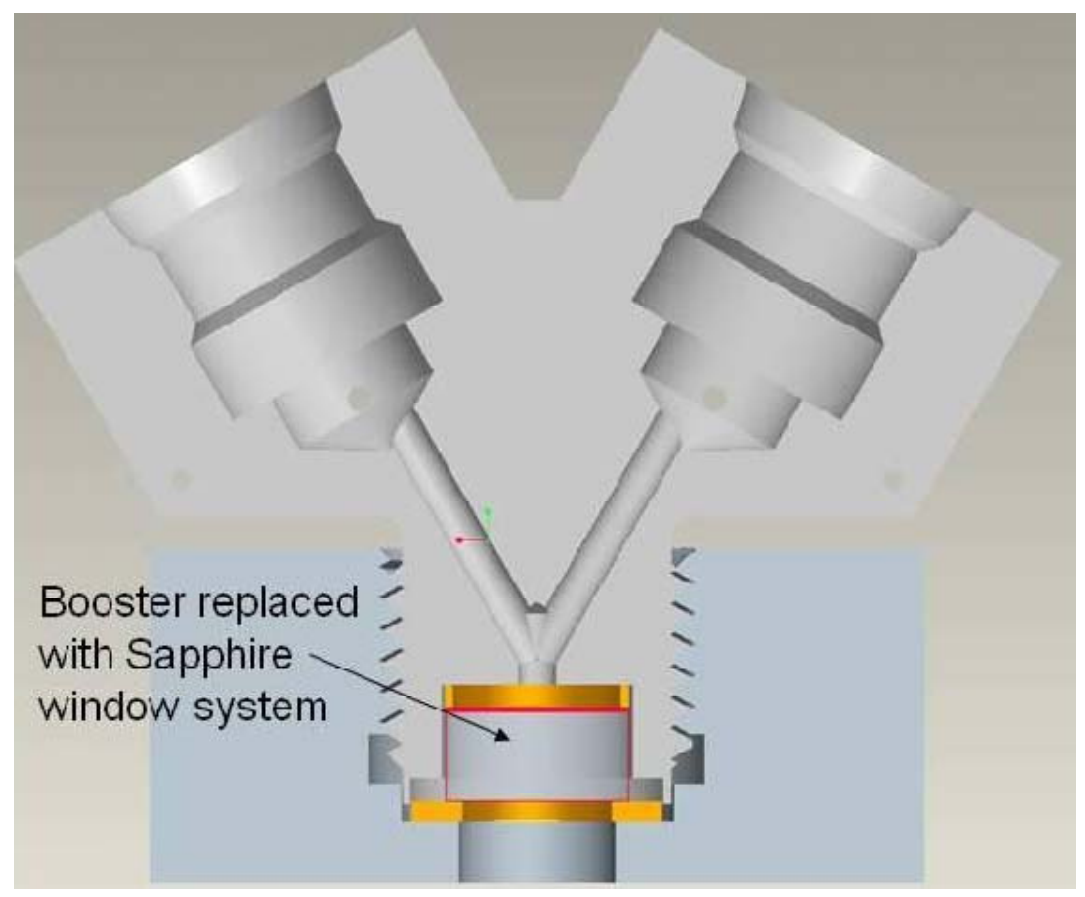

Figure 2. Sapphire Window Interface Simulating the Booster Container showing an Al Y-PCA.

The booster cover simulator was made from 304L SS supplied by the same vendor that makes the actual booster container. After the cover simulators were cut and before the tests, one side was sprayed with a very thin coating of flat black paint. This became the underside of the diaphragm and it provided a consistent emissivity for the infrared pyrometer. 
The window material, industrial sapphire, was chosen because of its excellent transmissivity in the infrared range. Only a 4 percent loss across the window was estimated. Since the same sapphire window material was used in all of the tests, this energy loss was consistent for all of the tests (Figure 3).

The sealing ring (Fig. 4 and 5) was made from either 17-4PH or 15-5PH SS. Concentric rings were cut in these extremely small pieces to make a labyrinth seal. The sealing arrangement was successfully hydrotested to 30,000 psig and did not leak.

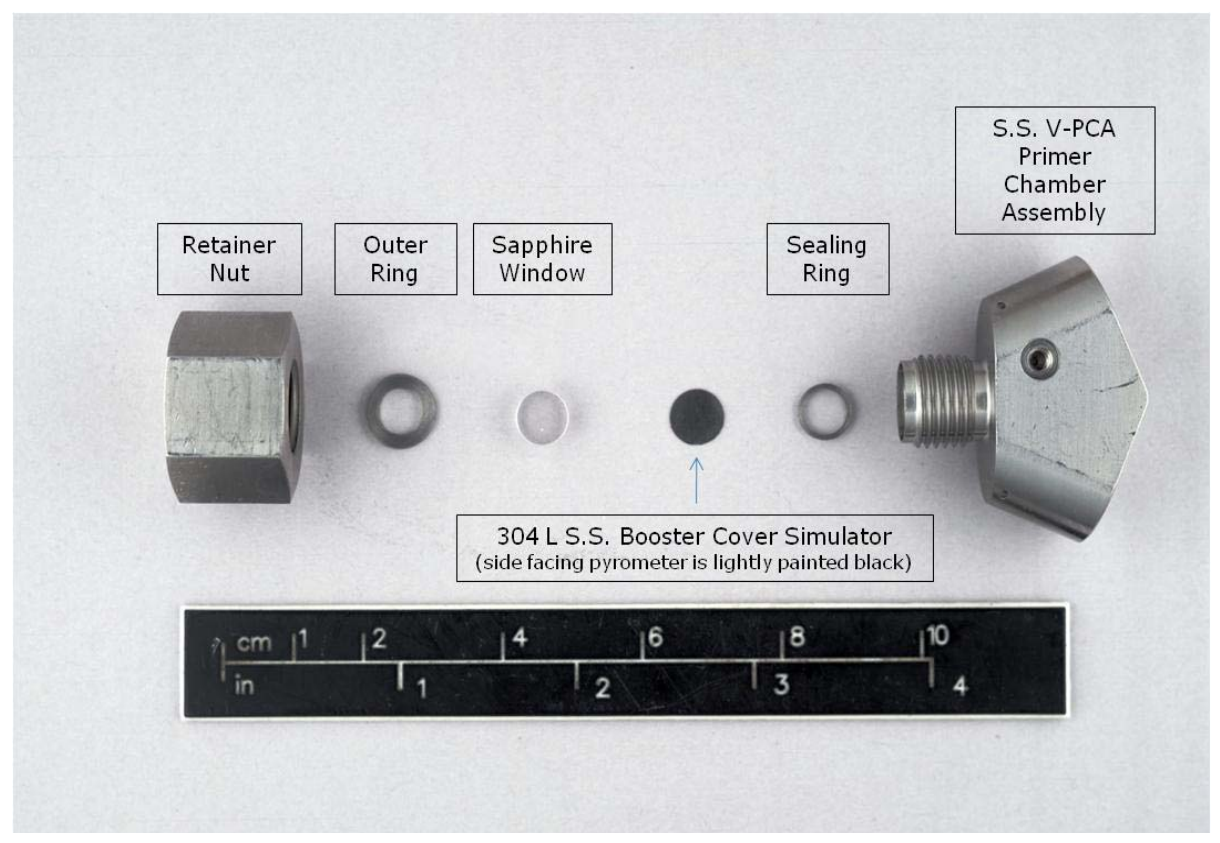

Figure 3. Sapphire Window System Parts showing a SS V-PCA.

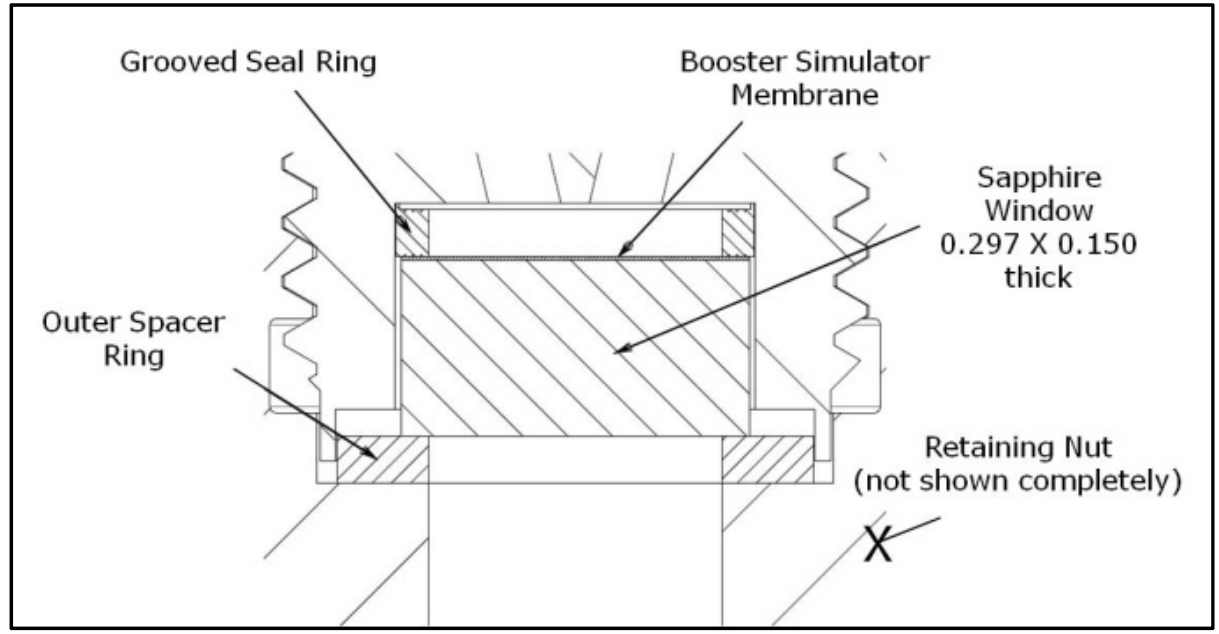

Figure 4. Sapphire Window Assembly. 


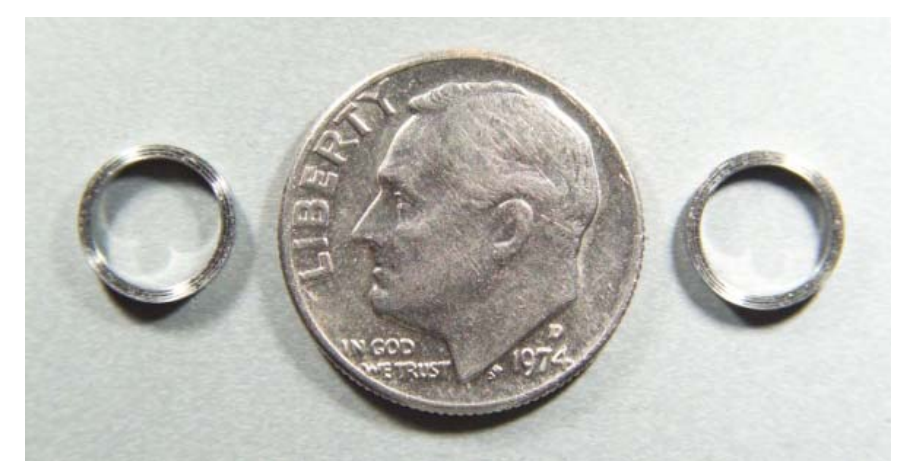

Figure 5. Sealing Rings Shown Alongside a U.S. Dime.

One pressure sense port for each NSI cavity was provided in the side of each PCA. The ports were made to accommodate Kistler model 603B1 pressure transducers. The ports were filled with Dow Corning 33 silicone grease. The infrared pyrometer used for the tests had a temperature range of 300 to $2,000{ }^{\circ} \mathrm{C}\left(572\right.$ to $\left.3,632{ }^{\circ} \mathrm{F}\right)$ with a nominal response time of $6 \mu \mathrm{s}$.

\section{Phase I, Y-PCA vs. V-PCA Testing}

In the first phase of this assessment, single and dual simultaneous firings of the NSIs were performed in both PCA types to characterize the peak temperature delivered to the booster membrane/propellant charge interface (underside of the booster charge cover). Figure 6 shows typical results from a single NSI firing in an Al Y-PCA and typical results for a single NSI firing in a SS V-PCA are shown in Fig. 7. The SS V-PCA units delivered an average maximum booster/propellant interface temperature $\sim 600^{\circ} \mathrm{F}$ greater than that delivered by the Al Y-PCA units. The Al Y-PCAs ignite the booster propellant reliably if not fired simultaneously, but this improvement provides extra margin. It is also noted that, under conditions of the tests, the higher temperature was achieved in half the rise time; $776 \mu$ s for the SS V-PCAs versus 1,342 $\mu$ s for the Al Y-PCAs. The SS V-PCA units produced pressures in the NSI cavity that averaged 3,000 psi greater than the Al Y-PCA units produced. Figure 8 compares the booster interface temperature results for all Phase I Tests.

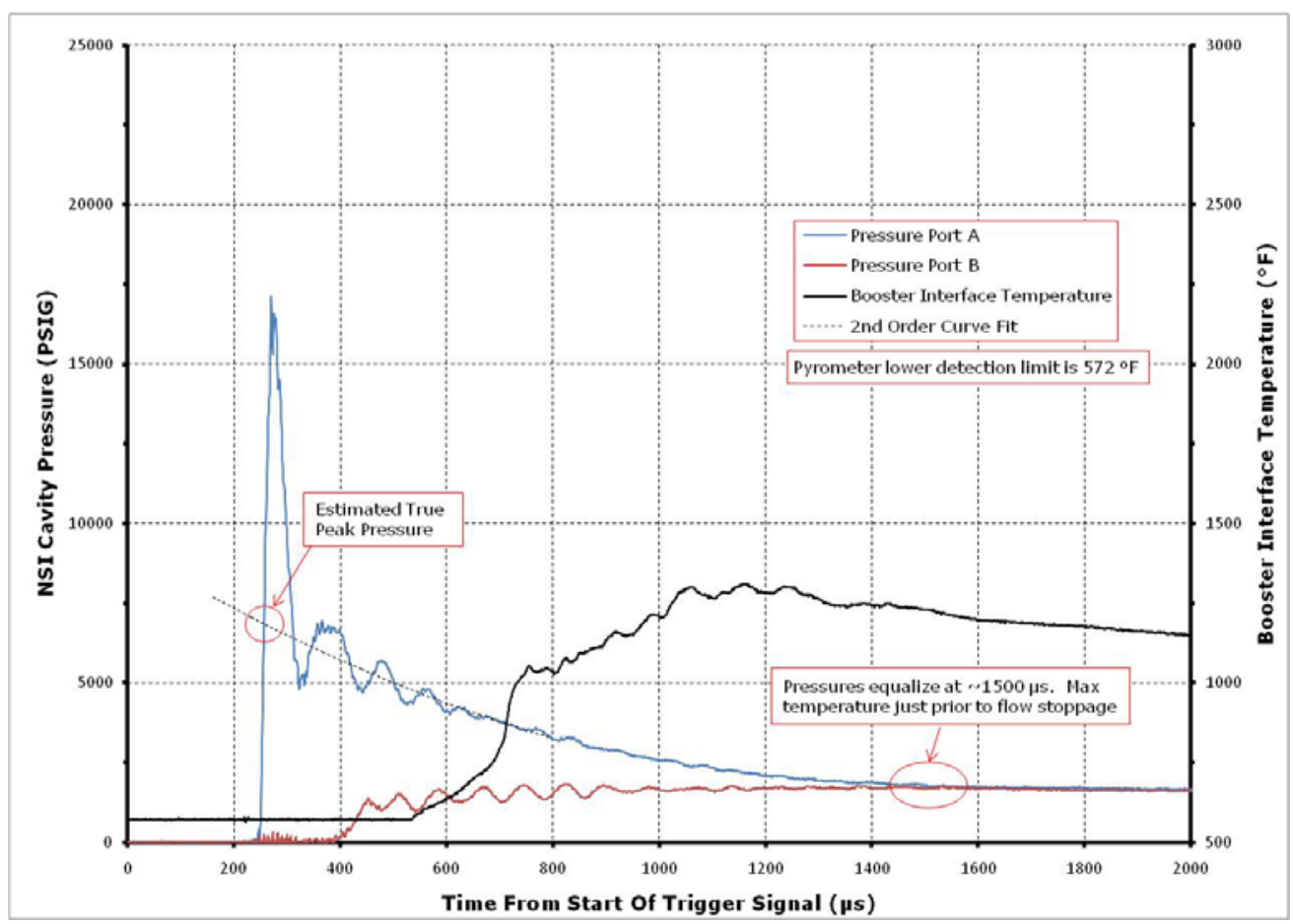

Figure 6. Typical Results from a Single NSI Firing in an Al Y-PCA (Run 4). 


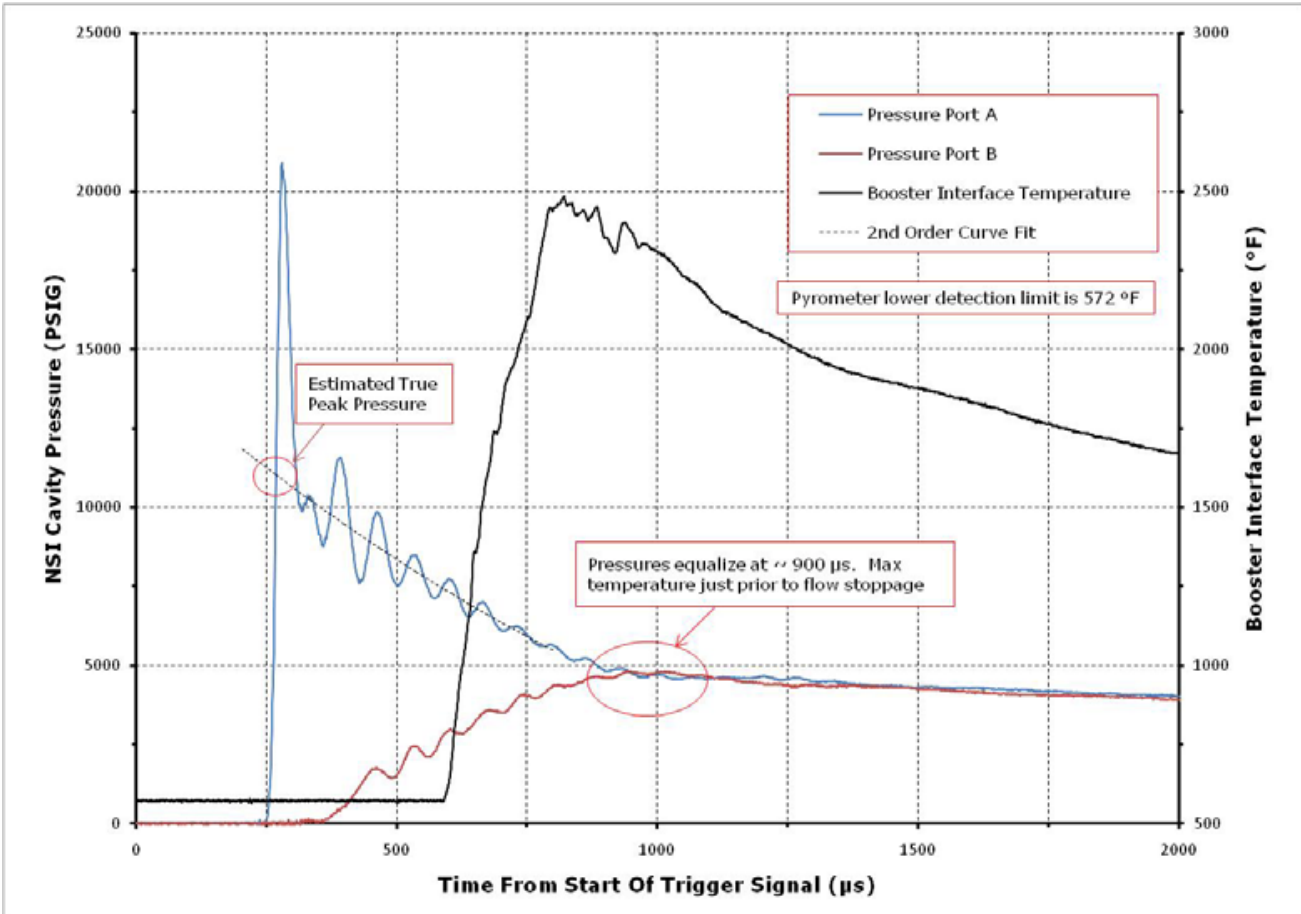

Figure 7. Typical Results for a Single NSI firing in a SS V-PCA (Run 15).

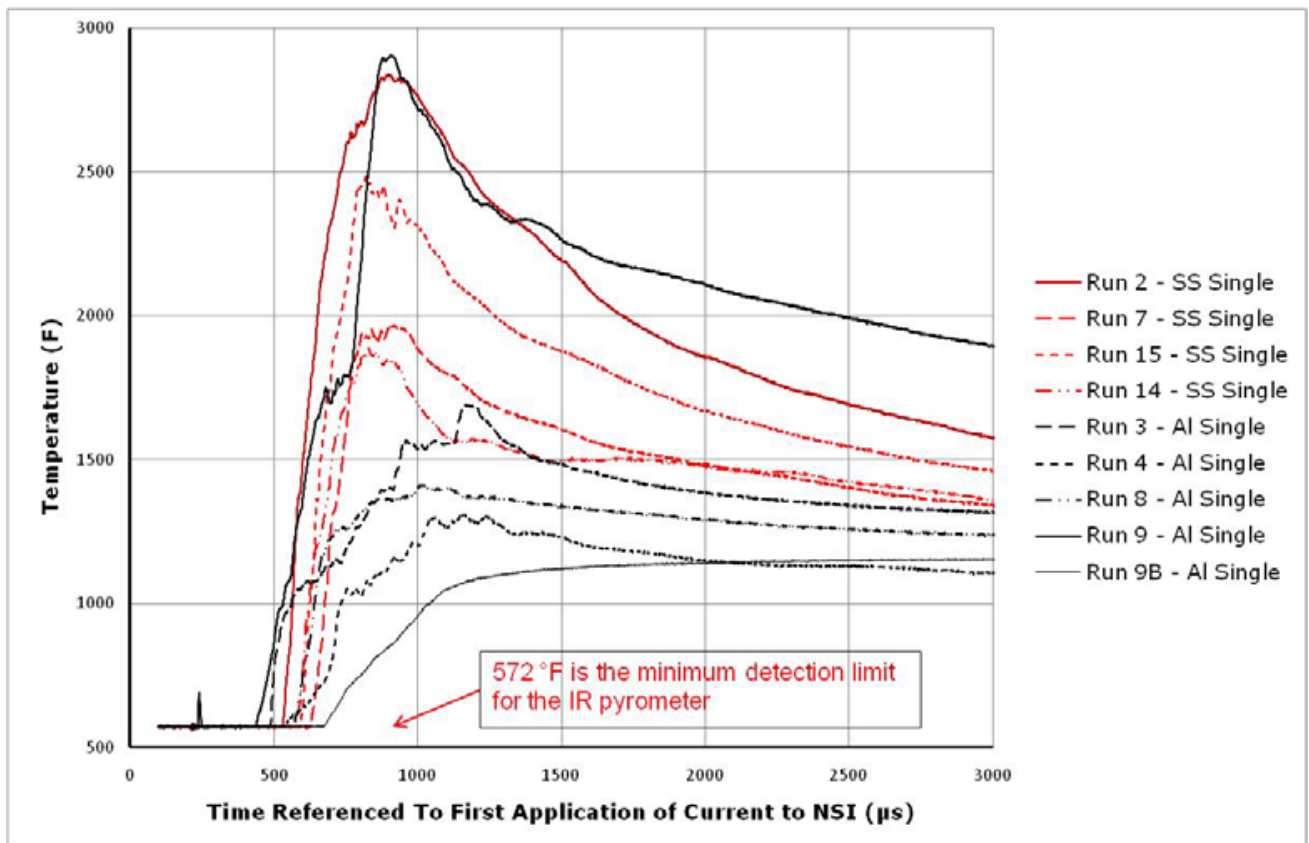

Figure 8. Booster Propellant Interface Temperature Results for all Phase I Tests. 
The tests showed that dual, simultaneous (within $20 \mu$ s) firing of the redundant NSIs significantly reduces the performance of either PCA design to the point where it is unlikely the booster charge would be reliably ignited. This is consistent with findings from previous NESC assessments. ${ }^{1}$ The booster interface temperature needed to ignite the titanium hydride/potassium perchlorate booster charge is $\sim 1,000{ }^{\circ} \mathrm{F}$. In some dual, simultaneous test firings, the maximum temperature observed was below or just slightly above the lower limit of $572^{\circ} \mathrm{F}$ that could be detected by the test instrumentation. Table 1 provides a Phase I Test Data Summary.

Table 1. Phase I Test Data Summary.

\begin{tabular}{|c|c|c|c|c|c|c|c|c|c|c|c|c|c|c|}
\hline \multicolumn{15}{|c|}{ Single NSI Firings } \\
\hline Run & $\begin{array}{c}\text { Al } \\
\text { - or - } \\
\text { SS }\end{array}$ & Date & Time & $\begin{array}{c}\text { Pressure } \\
\text { Start } \\
\text { Side A } \\
(\mu \mathrm{s}) \\
\end{array}$ & \begin{tabular}{|c|} 
Max \\
Pressure \\
Side A \\
(psig) \\
\end{tabular} & $\begin{array}{c}\text { Time Of } \\
\text { Max Press } \\
\text { Side A } \\
(\mu \mathrm{s}) \\
\end{array}$ & $\begin{array}{c}\text { Pressure } \\
\text { Start } \\
\text { Side B } \\
(\mu \mathrm{s}) \\
\end{array}$ & $\begin{array}{c}\text { Max } \\
\text { Pressure } \\
\text { Side B } \\
\text { (psig) } \\
\end{array}$ & $\begin{array}{c}\text { Time Of } \\
\text { Max Press } \\
\text { Side B } \\
(\mu \mathrm{s})\end{array}$ & \begin{tabular}{|c|} 
Max Booster \\
Interface \\
Temp \\
$\left({ }^{\circ} \mathrm{F}\right)$ \\
\end{tabular} & $\begin{array}{c}\text { Time Of } \\
\text { Max Temp } \\
(\mu \mathrm{s})\end{array}$ & $\begin{array}{c}\text { Pressure } \\
\text { at } 800 \mu \mathrm{s} \\
\text { Side A } \\
\text { (psig) }\end{array}$ & $\begin{array}{c}\text { Pressure } \\
\text { at } 800 \mu \mathrm{s} \\
\text { Side B } \\
(\mathrm{psig})\end{array}$ & $\begin{array}{c}\text { Booster } \\
\text { Interface } \\
\text { Temp at } \\
800 \mu \mathrm{s} \\
\left({ }^{\circ} \mathrm{F}\right) \\
\end{array}$ \\
\hline Pre & SS & $02 / 23 / 10$ & $13: 56$ & 137 & 11,851 & 151 & 332 & 4,996 & 830 & 2,679 & 716 & 4,777 & 4,840 & 2,669 \\
\hline 2 & SS & $02 / 24 / 10$ & $12: 34$ & 140 & 10,926 & 156 & 255 & 4,570 & 824 & 2,823 & 835 & 4,638 & 4,527 & 2,836 \\
\hline 7 & SS & \begin{tabular}{|l|}
$02 / 25 / 10$ \\
\end{tabular} & $9: 40$ & 147 & 10,781 & 166 & 324 & 4,996 & 787 & 1,967 & 821 & 4,933 & 4,979 & 1,957 \\
\hline 14 & SS & $02 / 25 / 10$ & $13: 41$ & 144 & 10,436 & 159 & 314 & 4,441 & 870 & 1,885 & 726 & 4,690 & 4,232 & 1,842 \\
\hline 15 & SS & $02 / 25 / 10$ & $14: 55$ & 147 & 11,085 & 169 & 259 & 4,805 & 845 & 2,485 & 721 & 4,811 & 4,614 & 2,352 \\
\hline \multicolumn{2}{|c|}{ Average } & & & 145 & 10,807 & 163 & 288 & 4,703 & 832 & 2,290 & 776 & 4,768 & 4,588 & 2,247 \\
\hline & & & & & & & & & & & & & & \\
\hline 3 & Al & $03 / 01 / 10$ & $13: 29$ & 130 & 8,001 & 156 & 319 & 2,269 & 1,440 & 1,691 & 1,064 & 3,857 & 1,716 & 1,404 \\
\hline 4 & $\mathrm{Al}$ & $02 / 26 / 10$ & $8: 48$ & 143 & 6,881 & 157 & 286 & 1,650 & 1,241 & 1,308 & 1,053 & 2,938 & 1,580 & 1,133 \\
\hline 8 & Al & $02 / 26 / 10$ & 9:29 & 138 & 8,199 & 154 & 297 & 1,860 & 1,480 & 1,412 & 913 & 3,337 & 1,307 & 1,264 \\
\hline 9 & Al & $03 / 01 / 10$ & 14:02 & 155 & 6,560 & 160 & 292 & 1,848 & 1,130 & 2,902 & 804 & 3,077 & 1,762 & 2,894 \\
\hline 9B & $\mathrm{Al}$ & 04/06/10 & & 137 & 9,445 & 154 & 307 & 2,149 & 1,445 & 1,154 & 2,875 & 3,892 & 1,820 & 846 \\
\hline \multicolumn{2}{|c|}{ Average } & & & 141 & 7,817 & 156 & 300 & 1,955 & 1,347 & 1,391 & 1,342 & 3,420 & 1,637 & 1,508 \\
\hline \multicolumn{15}{|c|}{ Dual Simultaneous NSI Firings } \\
\hline 6 & SS & $02 / 24 / 10$ & 15:06 & 152 & 10,419 & 168 & 151 & 9,735 & 168 & ---- & --- & 9,252 & 9,196 & --- \\
\hline 1 & $\mathrm{Al}$ & $03 / 01 / 10$ & 14:43 & 149 & 6,456 & 164 & 149 & 6,244 & 163 & 719 & 10,210 & 4,863 & 4,857 & --- \\
\hline \multicolumn{15}{|c|}{$\begin{array}{l}\text { NOTES: } \\
\text { 1. The pyrometer does not read temperatures below } 572{ }^{\circ} \mathrm{F} \text {. } \\
\text { 2. "Side A" refers to the the fired side in a single NSI firing test; "Side B" is inert. } \\
\text { 3. All times are measured from the start of the firing pulse (increase in amps) }\end{array}$} \\
\hline
\end{tabular}

\section{Phase II, Effects of NSI Ignition Skew and PCA Passages Cross-sectional Area Changes}

The second phase of the assessment evaluated the effects of various NSI ignition delays (skews) and PCA flow passages of greater cross-sectional areas. The SS V-PCAs were modified to have NSI flow passages with crosssectional areas 2 and 4 times larger than the original design. The ignition circuitry was modified to allow variable NSI ignition delays (skews).

The second phase tests showed that even with flow paths having four times the original cross-sectional area, dual, simultaneous (within $20 \mu \mathrm{s}$ ) firings of the redundant NSIs significantly reduces performance to the point where it is doubtful the booster charge would be reliably ignited.

The flow paths with enlarged cross-sections (areas 2 and 4 times greater than the original design) did not consistently produce significantly higher temperatures at the booster interface. Some firings with larger flame passages did result in higher membrane temperatures while others did not.

When the flow path diameter and the skew are high, they exert a considerable downward effect on peak pressure. The flow paths with cross-sectional areas 2 and 4 times greater than the original design produced lower pressures in the NSI cavity. The reduction was about 1,600 and 2,400 psi, respectively. This was not unexpected due to the larger free volume with enlarged flow paths. Firings with attenuated temperatures and membrane and lower burn-through percentages occurred predictably at zero skew. The assessment successfully characterized the greater margin for booster ignition provided by the SS V-PCA design over the heritage Al Y-PCA design. However, either the Al or SS PCA will reliably ignite the booster as long as adequate NSI firing skew is used. The SS PCA provides improved ignition margin and resistance to burn-through, but has increased weight. The Al PCA has less weight with less 
ignition margin and slower ignition times. With either design, the ignition of both NSIs within $20 \mu$ s or less of each other has a significant probability of failure to ignite the booster charge. Designers of spacecraft and pyrovalves now have additional information to make informed decisions regarding the trade-off between the greater weight and improved performance of the SS V-PCA. The team was able to characterize the time and pressure histories for various skew times and flame channel areas. The testing did not show consistent improvement with larger NSI flow channels with either greater temperatures at the booster interface or a reduced probability of failure with dual, simultaneous NSI firings. In addition to thermal analysis done by the team, SS PCA modeling was accomplished by Combustion Research and Flow Technology, Inc. (Craftech Industries, Inc.) under the Small Business Innovation Research (SBIR) program in collaboration with this project. This helped provide an understanding of the booster stagnation condition that results from a simultaneous NSI firing. The modeling also suggested that additional chambers machined into the PCA might help preclude the stagnation condition and eliminate the anomaly. A single test was tried with small chambers machined in, but did not clearly demonstrate an improvement. A further increase in the volume of these chambers and additional testing would likely be necessary to reach firm conclusions on the merit of this modification. Table 2 is a summary of Phase II Test Data.

Because the assessment did not conduct tests with booster charges in place, the overall ability to drive the ram and actuate the pyrovalve could not be examined. This ability could be reduced by the increased tendency of the booster gases to flow back up the enlarged flow passages towards the NSI cavities and by the increase in free volume in the PCA with larger flame passages. Significant testing at the pyrovalve assembly level would be needed to fully understand the effect of larger flame passages. The larger flow channels are a significant departure from both the heritage Al Y-PCA and SS V-PCA flight-qualified designs.

Table 2. Phase II Test Data Summary.

\begin{tabular}{|c|c|c|c|c|c|c|c|c|c|c|}
\hline $\begin{array}{c}\text { Test } \\
\text { Phase }\end{array}$ & $\begin{array}{l}\text { Run } \\
\text { No. }\end{array}$ & $\begin{array}{c}\text { Channel } \\
\text { Diameter } \\
\text { (in.) }\end{array}$ & $\begin{array}{c}\text { Actual } \\
\text { Skew } \\
(\mu \mathrm{s})\end{array}$ & $\begin{array}{c}\text { Max } \\
\text { Pressure } \\
\text { Side A } \\
\text { (psig) }\end{array}$ & $\begin{array}{c}\text { Time of } \\
\text { Max } \\
\text { Press } \\
\text { Side A } \\
(\mu s)\end{array}$ & $\begin{array}{c}\text { Max } \\
\text { Booster } \\
\text { Interface } \\
\text { Temp } \\
\left({ }^{\circ} \mathrm{F}\right)\end{array}$ & $\begin{array}{c}\text { Time of } \\
\text { Max } \\
\text { Booster } \\
\text { Interface } \\
\text { Temp } \\
(\mu \mathrm{s}) \\
\end{array}$ & $\begin{array}{l}\text { Press } \\
\text { Before } \\
\text { Side B } \\
\text { Rise } \\
\text { (psig) } \\
\end{array}$ & $\begin{array}{c}\text { Max } \\
\text { Pressure } \\
\text { Side B } \\
\text { (psig) } \\
\end{array}$ & $\begin{array}{c}\text { Time of } \\
\text { Max } \\
\text { Press } \\
\text { Side B } \\
(\mu \mathrm{s})\end{array}$ \\
\hline $2 \mathrm{~B}$ & 1 & 0.060 & 6 & 10,437 & 225 & - & NA & NA & 9,781 & 235 \\
\hline $2 \mathrm{~A}$ & $3 \mathrm{~A}$ & 0.060 & 16,000 & 9,641 & 224 & 3,410 & 16,434 & 1,574 & 13,039 & 16,057 \\
\hline $2 \mathrm{~B}$ & 4 & 0.060 & 486 & 11,389 & 224 & 2,913 & 1,132 & 2,532 & 15,076 & 713 \\
\hline $2 \mathrm{~B}$ & 5 & 0.060 & 485 & 10,780 & 220 & 3,078 & 1,161 & 5,661 & 15,371 & 710 \\
\hline $2 \mathrm{~B}$ & 7 & 0.060 & 5 & 9,715 & 223 & 1,723 & 217 & $\mathrm{NA}$ & 10,719 & 229 \\
\hline $2 \mathrm{~B}$ & 11 & 0.060 & 235 & 10,670 & 228 & 2,275 & 825 & 2,494 & 13,344 & 460 \\
\hline Average & & & 10,439 & 224 & 2,680 & 3,954 & 3,065 & 12,888 & \multicolumn{2}{|c|}{3,067} \\
\hline $2 \mathrm{~A}$ & 4 & 0.085 & 16,000 & 7,838 & 225 & 3,402 & 16,460 & 1,456 & 10,145 & 16,052 \\
\hline $2 \mathrm{~B}$ & $2 \mathrm{~B}$ & 0.085 & 236 & 8,618 & 222 & 1,837 & 2,555 & 3,018 & 13,734 & 466 \\
\hline $2 \mathrm{~B}$ & $6 \mathrm{~A}$ & 0.085 & 250 & 9,440 & 212 & 1,896 & 1,578 & 5,765 & 12,212 & 461 \\
\hline $2 \mathrm{~B}$ & 8 & 0.085 & 0 & 10,010 & 240 & 2,095 & 246 & NA & 10,477 & 240 \\
\hline $2 \mathrm{~B}$ & 13 & 0.085 & 237 & 9,017 & 219 & 1,733 & 1,208 & 3,208 & 14,220 & 459 \\
\hline $2 \mathrm{~B}$ & 9 & 0.085 & 242 & 8,493 & 222 & 2,517 & 965 & 3,140 & 13,094 & 461 \\
\hline $2 \mathrm{~B}$ & $14 \mathrm{~A}$ & 0.085 & 8 & 9,637 & 224 & 1,723 & 220 & NA & 10,146 & 232 \\
\hline $2 \mathrm{~B}$ & 16 & 0.085 & 484 & 8,435 & 222 & 3,312 & 803 & 4,074 & 14,027 & 717 \\
\hline $2 \mathrm{~B}$ & 17 & 0.085 & 236 & 8,828 & 220 & 2,315 & 770 & 3,052 & 12,826 & 468 \\
\hline Average & & & 8,924 & 223 & 2,314 & 2,756 & 3,388 & 12,320 & \multicolumn{2}{|c|}{2,173} \\
\hline $2 \mathrm{~A}$ & $1 \mathrm{~A}$ & 0.120 & 12 & 9,321 & 168 & - & NA & NA & 8,908 & 156 \\
\hline $2 \mathrm{~A}$ & 2 & 0.120 & 16,000 & 6,852 & 213 & 3,479 & 16,285 & 1,562 & 9,692 & 16,211 \\
\hline $2 \mathrm{~B}$ & $3 \mathrm{~A}$ & 0.120 & 488 & 8,243 & 214 & 3,630 & 299 & 4,140 & 10,114 & 700 \\
\hline $2 \mathrm{~B}$ & 10 & 0.120 & 243 & 7,500 & 219 & 2,501 & 648 & 3,528 & 11,546 & 458 \\
\hline $2 \mathrm{~B}$ & 12 & 0.120 & 5 & 9,208 & 215 & 1,957 & 216 & NA & 9,785 & 221 \\
\hline $2 \mathrm{~B}$ & 14 & 0.120 & 484 & 7,208 & 219 & 3,630 & 774 & 3,528 & 10,389 & 706 \\
\hline 2B & 15 & 0.120 & 5 & 9,161 & 222 & 699 & 3,700 & NA & 9,077 & 237 \\
\hline Average & & & 8,213 & 210 & 2,649 & 3,654 & 3,190 & 9,930 & \multicolumn{2}{|c|}{2,670} \\
\hline \multicolumn{11}{|c|}{$\begin{array}{l}\text { NOTES: } \\
\text { 1. All times are from the start of the firing signal. } \\
\text { 2. A red highlight indicates a temperature too low to ignite the booster propellant. } \\
\text { 3. A dash "-" indicates a temperature lower than the } 572^{\circ} \mathrm{F} \text { lower limit detectable by the pyrometer. This means that } \\
\text { the temperature could be anywhere between } 72^{\circ} \mathrm{F} \text { and } 572^{\circ} \mathrm{F} \text {. }\end{array}$} \\
\hline
\end{tabular}




\section{PCA Thermal Analysis}

To better understand the contribution of various heat transfer mechanisms in the PCA, both simplified and detailed thermal analyses were performed by the NASA Technical Fellow for Passive Thermal and his NESC Technical Discipline Team. ${ }^{2}$ Three heat transfer mechanisms and their effect on booster cap thermal response were investigated as part of this study. From the analysis, the following conclusions are drawn:

a. Convective heat transfer, by itself, does not account for the temperature rise and melting during booster cap testing;

b. Deposition of liquid zirconia spray onto the booster cap results in more heat transfer than convection alone. Zirconia deposition and the subsequent phase change from the liquid to solid state may assist in booster cap heating and subsequent melting, but does not produce booster cap temperatures in agreement with the booster cap transient temperature response observed during testing. Larger quantities of zirconia deposition increase the propensity to melt and accelerate the temperature rise of the booster cap bottom;

c. Detailed thermal analysis suggests that a hemispherical globule of zirconium-potassium perchlorate (ZPP) with a radius of $3.6 \times 10-3$ in. with a mass of $5.2 \times 10^{-3} \mathrm{mg}\left(1.14 \times 10^{-8} \mathrm{lbm}\right)$ can liberate sufficient energy to locally melt through the booster cap.

Deposition of as little as 20 percent of the unburned ZPP $\left(\sim 4.6 \mathrm{mg}\right.$, or $\left.1 \times 10^{-5} \mathrm{lbm}\right)$ can liberate sufficient energy to melt the entire booster cap. Subsequent two-dimensional axisymmetric thermal analysis shows that local meltthrough can be accomplished with considerably less ZPP. From this, it is concluded that $<4.6 \mathrm{mg}$ ZPP burning in contact with the booster cap is sufficient to produce the observed response.

\section{Statistical Analysis and Results}

The Phase I test was designed using some design of experiments (DOE) methods. The statement of problem was clearly developed. The size of the test was governed by resource considerations rather than a quantitative statement regarding a confidence level on a difference the team desired to be able to find, but the subject matter experts had reason to believe this test would be sufficient to show clear and useful differences. They were correct in this assessment, as will be seen. ${ }^{3}$

Phase IIB was designed to evaluate the relationship between firing skew and the cross-sectional area of the flow passages. It was assumed that the following model would apply:

$$
\mathrm{Y}=\beta_{0}+\beta_{1} \text { Skew }+\beta_{2} \text { Area }+\beta_{12} \text { Skew x Area }+\beta_{11} \text { Skew }^{2}+\beta_{22} \text { Area }^{2}
$$

where the $\beta$ 's are linear regression parameters fit using the data.

The statistical analysis of the results confirmed clearly that within the tested range of the two inputs studied, no-fires were entirely possible at low skews. A no-fire in this test at high skew and channel area suggests that the channel area does not mitigate the risk of a no-fire, and a no-fire at more than $500 \mu \mathrm{s}$ could occur. Temperatures increase with increasing skew, but are fairly insensitive to channel area. Channel area affects pressure and increases variability of the time it takes to attain peak temperature. ${ }^{4}$

\section{Numerical Simulations of Single and Simultaneous Dual Firing NSIs in the SS VPCA Design}

In addition to the PCA thermal analysis discussed in Section V, SS PCA numerical simulations (computer modeling) were accomplished by Craftech under the SBIR program, in collaboration with this project. Details of this modeling are provided in the final report. ${ }^{5}$ This numerical modeling effort, based on computational fluid dynamics, provided an improved understanding of the gas and particle flow physics within the V-PCA. One of the primary issues explored by this test project, the dual, simultaneous NSI ignition anomaly was explained as interaction of the shocks formed by the two NSIs and stagnation at the booster interface. The computer modeling indicated that the stagnation condition and reflected waves reduce the amount of hot, burning ZPP particles reaching the booster membrane, causing the membrane temperature to be dramatically lower. Modeling of a modified V-PCA with additional volume chambers on either side of the flow channels was also accomplished. 


\section{Conclusions}

Although the AL Y-PCA has demonstrated the ability to consistently ignite a booster with a single NSI firing, or when the firing skew is greater than $2 \mathrm{~ms}$, the SS V-PCA units avoid flame passage melting and erosion, energy loss, and potential leakage of the NSI flow products. The V-PCA units demonstrated improved performance in that the average maximum booster/propellant interface temperature was $\sim 600^{\circ} \mathrm{F}$ greater than that delivered by the $\mathrm{Al} \mathrm{Y}$ PCA units. The higher temperatures delivered to the booster interface provide added assurance of booster propellant ignition. The higher temperatures with the SS V-PCAs were achieved in approximately half the time; $776 \mu$ s average for the SS V-PCAs versus 1,342 $\mu$ s average for the Al Y-PCAs. This has resulted in faster ignition of the booster as demonstrated in other related testing.

The SS V-PCA units produced pressures in the NSI cavity that were also $\sim 3,000$ psi greater than the Al Y-PCA units. However, the testing showed that dual, simultaneous (within $20 \mu \mathrm{s}$ ) firing of the redundant NSIs significantly reduces the performance of either PCA design to the point where it is doubtful the booster charge would be reliably ignited. The booster interface temperature needed to ignite the titanium hydride/potassium perchlorate booster charge is $\sim 1,000{ }^{\circ} \mathrm{F}$ under rapid rise conditions present in the pyrovalve. In about 50 percent of the dual, simultaneous test firings, the maximum temperature observed was below or just slightly above the lower limit of $572{ }^{\circ} \mathrm{F}$ that could be detected by the test instrumentation. Also in Phase II, even with flow paths enlarged to 4 times the original cross-sectional area, test data indicated that dual simultaneous (within $20 \mu \mathrm{s}$ ) firings of the redundant NSIs significantly reduces performance to the point where it is again doubtful the booster charge would be reliably ignited. The assessment did not show consistent improvement with larger NSI flow channels, either with greater temperatures at the booster interface or a reduced probability of failure with dual, simultaneous NSI firings. Statistical analysis was used to ensure good experiment design and to help judge the significance of the test results. Thermal analysis was accomplished, which helped the team understand the processes in which heating of the diaphragm occurs so rapidly. This provided insight into the burning zirconia spray environment at the booster interface. Numerical simulation of single and simultaneous dual firing NSIs gave insight into the reasons very low skew firings resulted in such low temperatures at the SS V-PCA booster interface. Two-dimensional animations were provided that show how the shock reflections actually caused burning particulate to be carried away from the booster interface.

It was recommended that the SS V-PCA be used on future NASA programs since the improved ignition margin and erosion resistance makes it more robust (unless weight factors dictate otherwise). This is deemed especially important for manned spaceflight applications, such as on the Multi-Purpose Crew Vehicle (Orion).

\section{References}

\footnotetext{
${ }^{1}$ NESC Report No.: RP-08-111_06-009-E, Conax Y-PCA (Primer Chamber Assembly) Booster Anomaly Investigation, October 30, 2008.

${ }^{2}$ This full analysis is available in Appendix E of NESC Final Report: Comparison of the Booster Interface Temperature with the New Stainless Steel Primer Chamber Assembly (V-PCA) versus the Legacy Aluminum Y-PCA, submitted for publication.

${ }^{3}$ Ibid., Appendix F.

${ }^{4}$ Ibid., Appendix G.

${ }^{5}$ Ibid., Appendix H.
} 


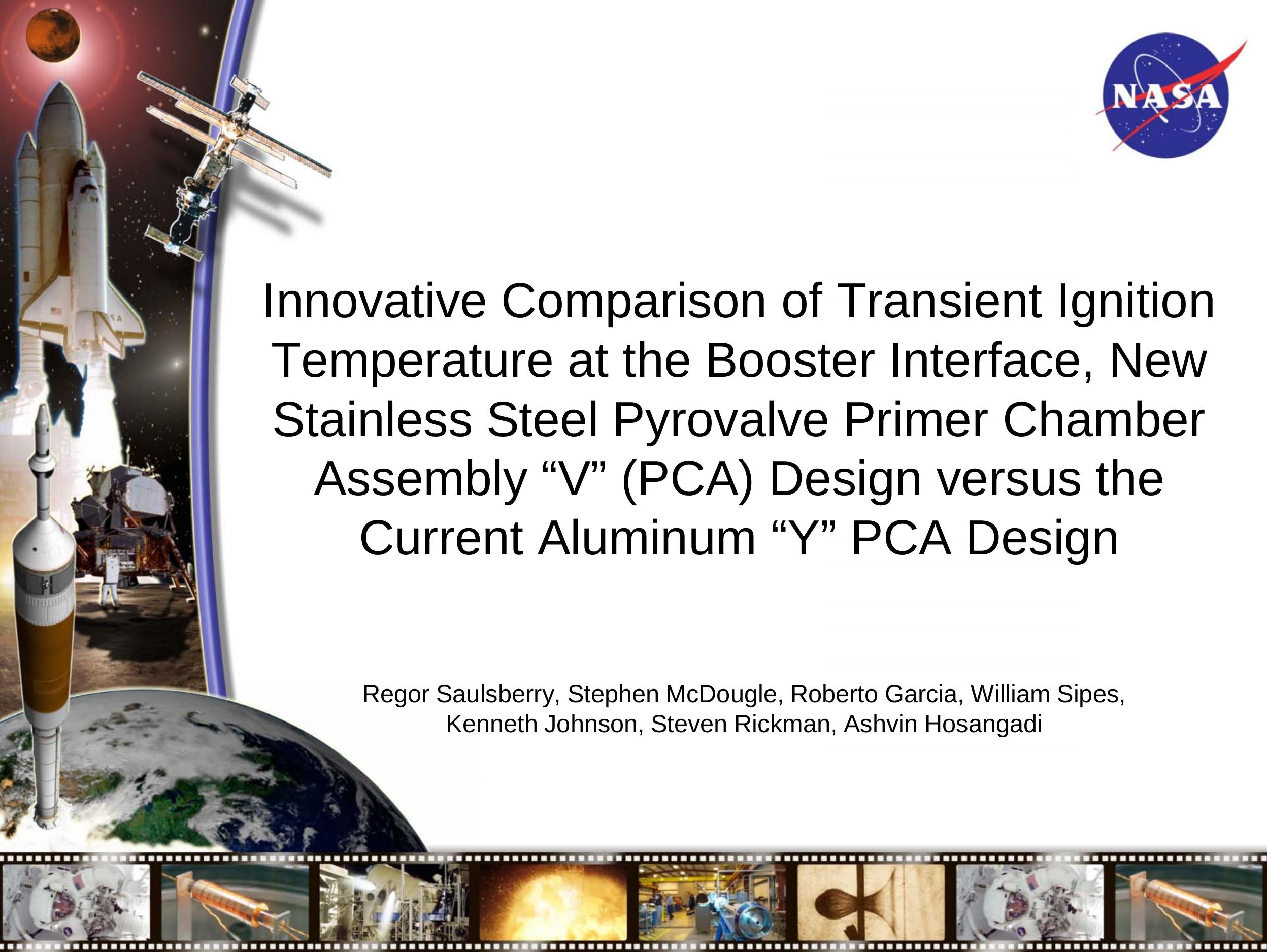


- In 2008, the NASA Engineering \& Safety Center (NESC) investigated four spacecraft pyrovalve anomalies that occurred during ground testing:

- All had a common aluminum (Al) primer chamber assembly (PCA) with dual NASA Standard Initiators (NSIs)

- Nearly simultaneous (separated by less than 80 microseconds $(\mu \mathrm{s})$ ) firing of both initiators failed to ignite the booster charge

- The results of the assessment and associated test program were reported in AIAA Paper AIAA-2008-4798, NESC Independent Assessment of Pyrovalve Ground Test Anomalies 
- Based on the NESC report, the Mars Science Laboratory (MSL) project team evaluated design changes to the pyrovalves:

- PCAs would be made from stainless steel (SS) instead of Al

- The internal flow passages would be " $V$ " instead of " $Y$ " shaped

- The changes had two goals:

- Provide extra margin for booster charge ignition

- Reduce possibility of burning through the side of the PCA 


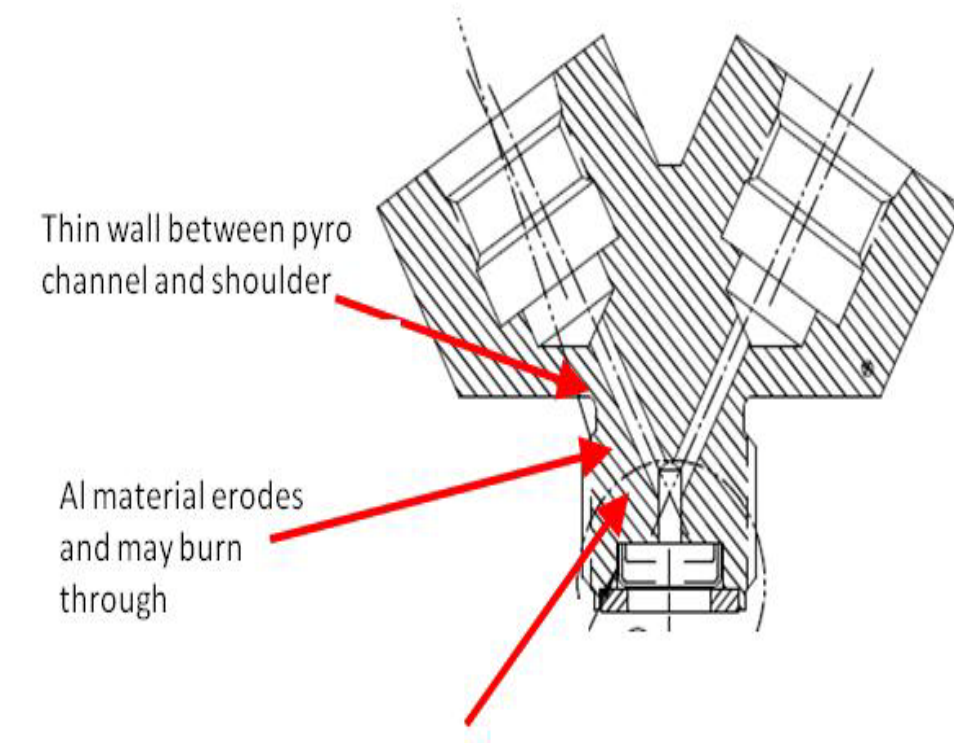

Change in flow direction due to Y-configuration may

compromise ignition

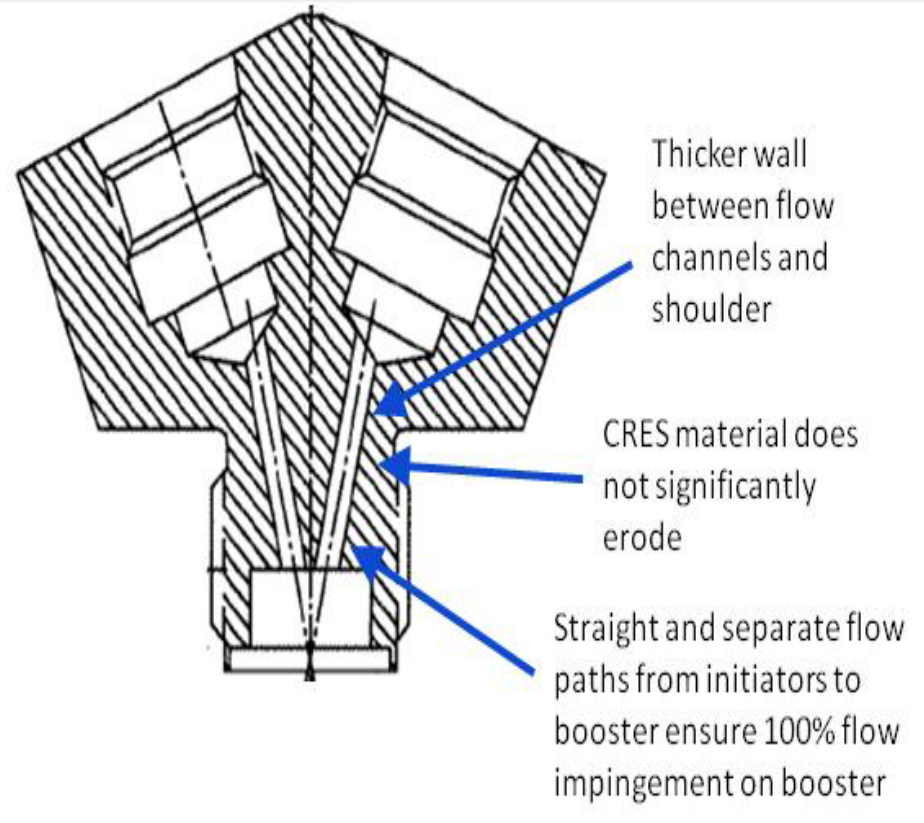

MSL: CRES-V

- Empirical testing by Lockheed-Martin showed that the new design provided extra ignition margin

- The final NESC report of the ground test anomalies recommended that the two PCA types be experimentally and quantitatively compared prior to widespread application by NASA programs 


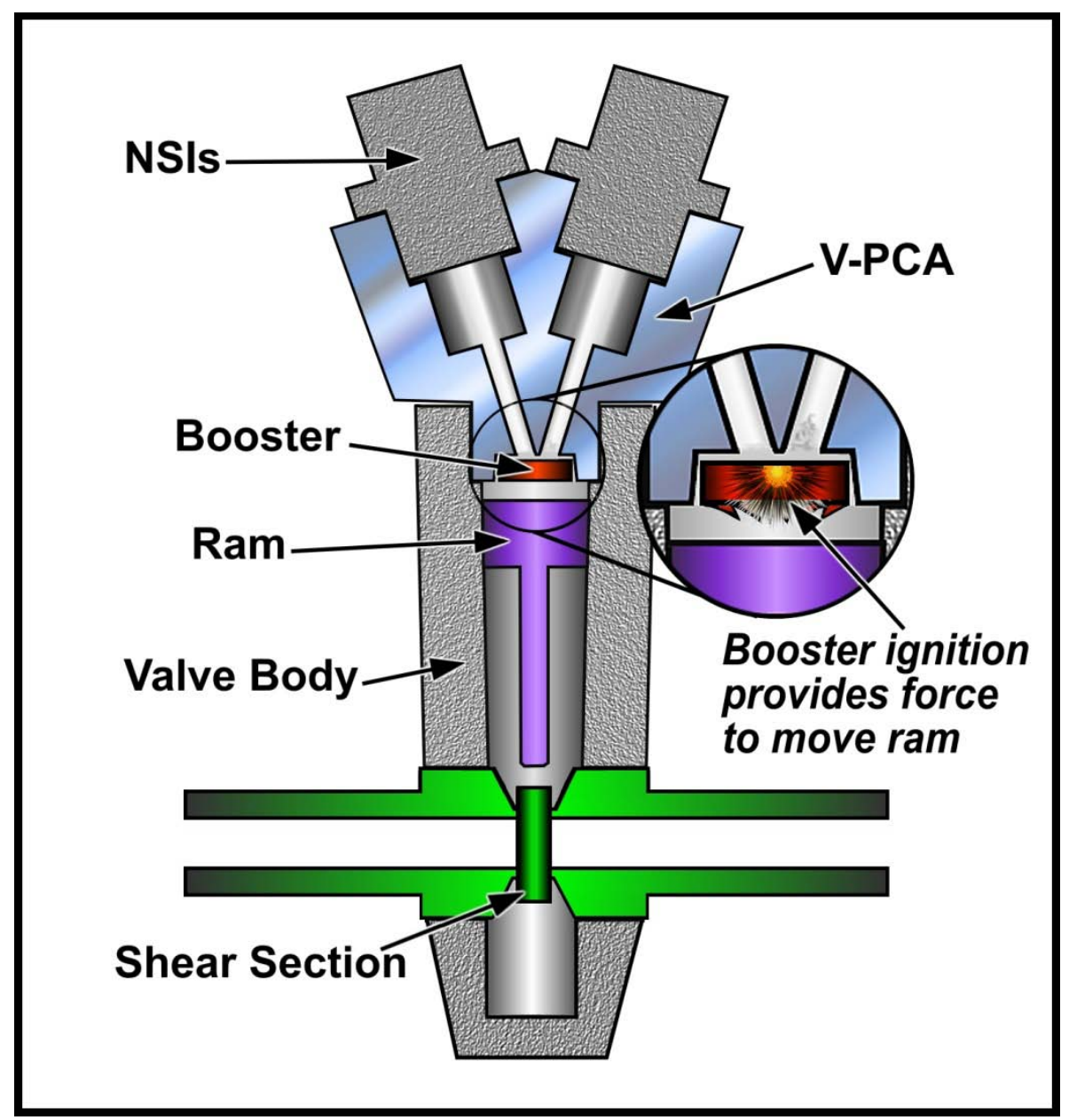

Normally Closed (NC) Pyrovalve Block Diagram (SS V-PCA) 
- Phase I-Compare temperature at the booster charge interface for both PCA types

- Use methodologies and equipment developed previously, but improve the sapphire window sealing arrangement at the booster interface

- Perform single NSI and dual, simultaneous (<10 $\mu$ s skew) NSI firings

- Phase II - Consisted of two parts to further evaluate the SS V-PCA

- Phase IIA - Evaluate different NSI flow channel cross-sectional areas with single and dual, simultaneous NSI firings

- Phase IIB - Evaluate staggered NSI firing times and flow channel cross-sectional areas

This briefing is for status only and does not represent complete

engineering data analysis 


\section{Sapphire Window Assembly}

Underside of Booster Cover Simulator (0.003-in CRES) to be Viewed with High Speed Optical Pyrometers and Video Cameras

NOTE: Legacy Al Y-PCA Shown Here

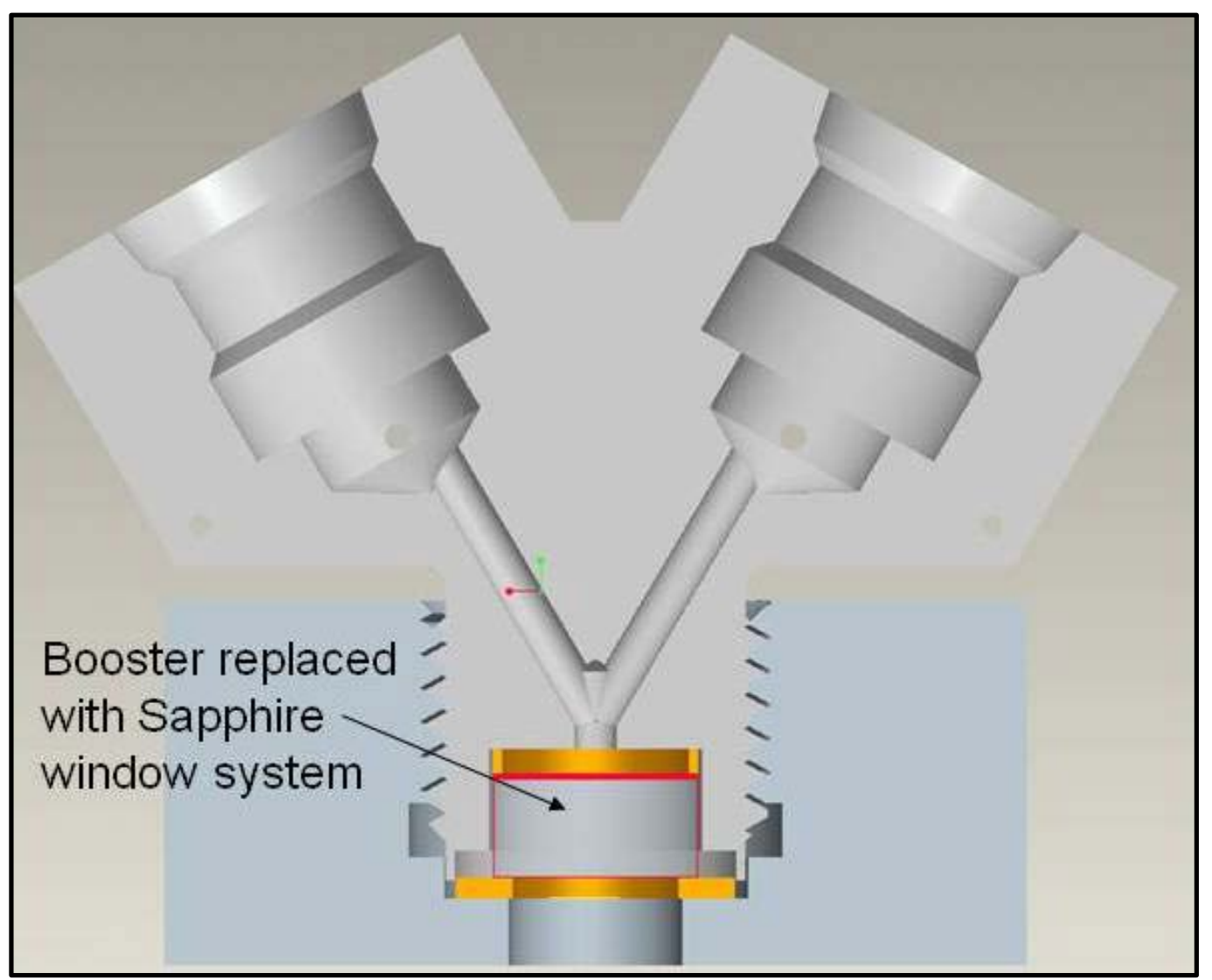




\section{Sapphire Window System Parts}

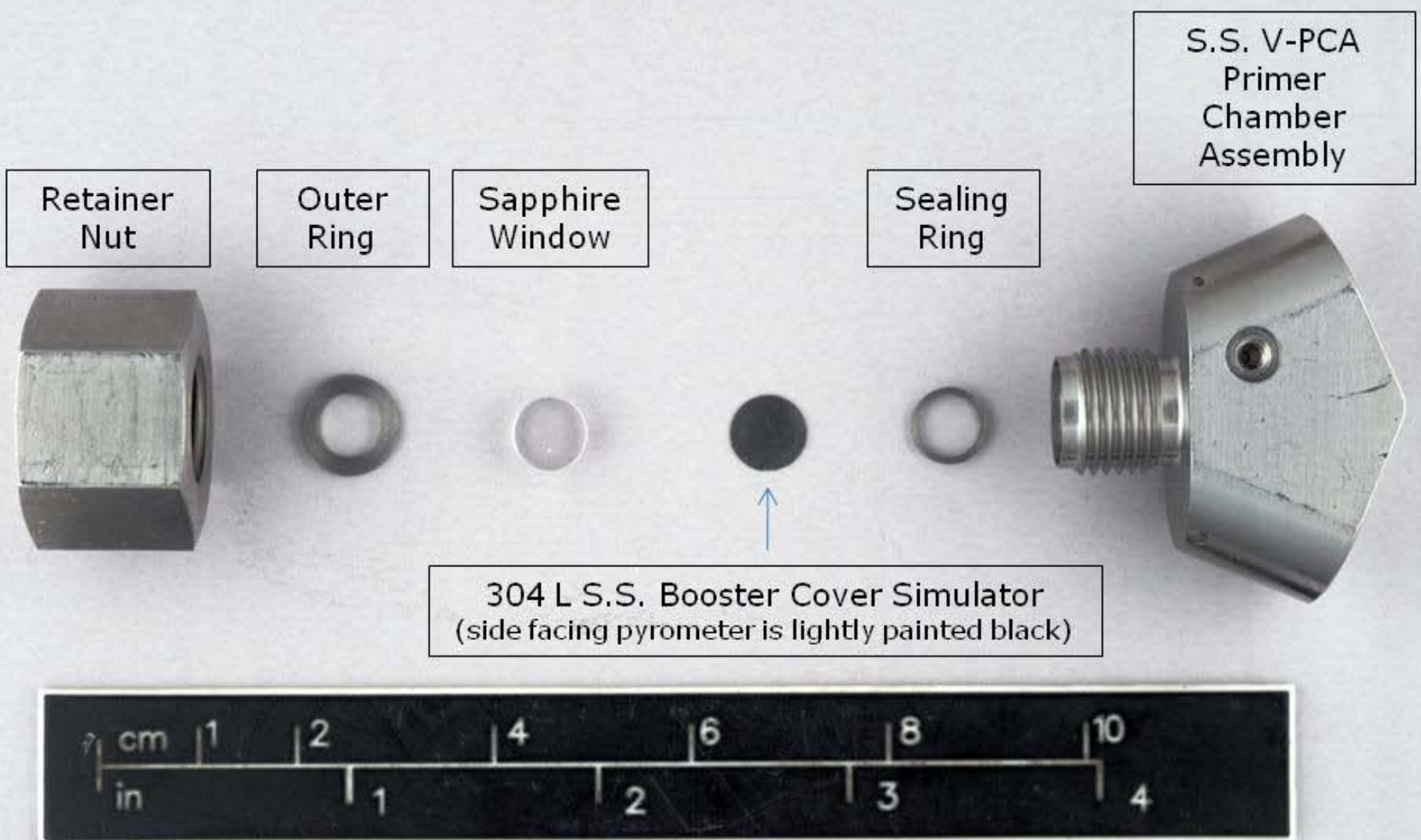

Sapphire Window Parts (SS V-PCA Is Shown) 


\section{Improved Sealing Ring Design}

- Made from either 17-4PH or 15-5PH stainless steel

- Concentric rings were cut in the sealing surface to make a labyrinth seal

- Hydro-tested to 30,000 psig with no leakage

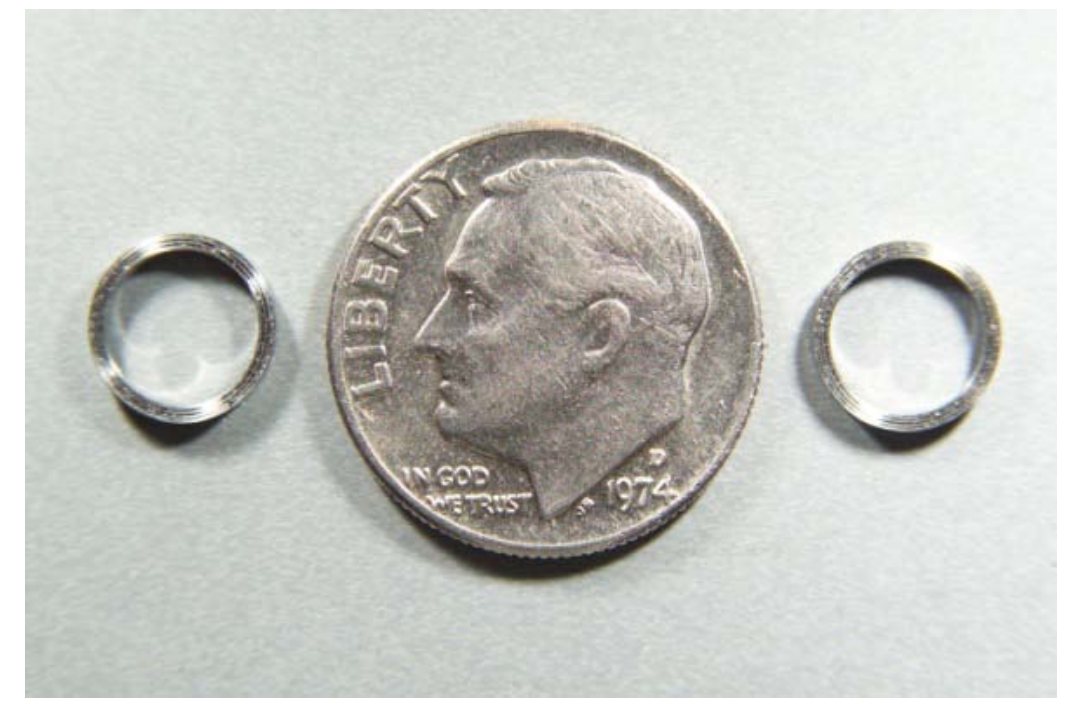

Sealing Rings Shown

Alongside a U.S. Dime

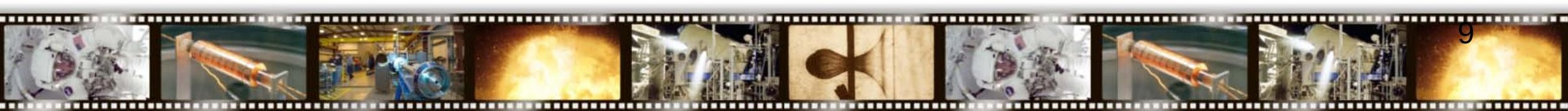




\section{Overall Test Setup}

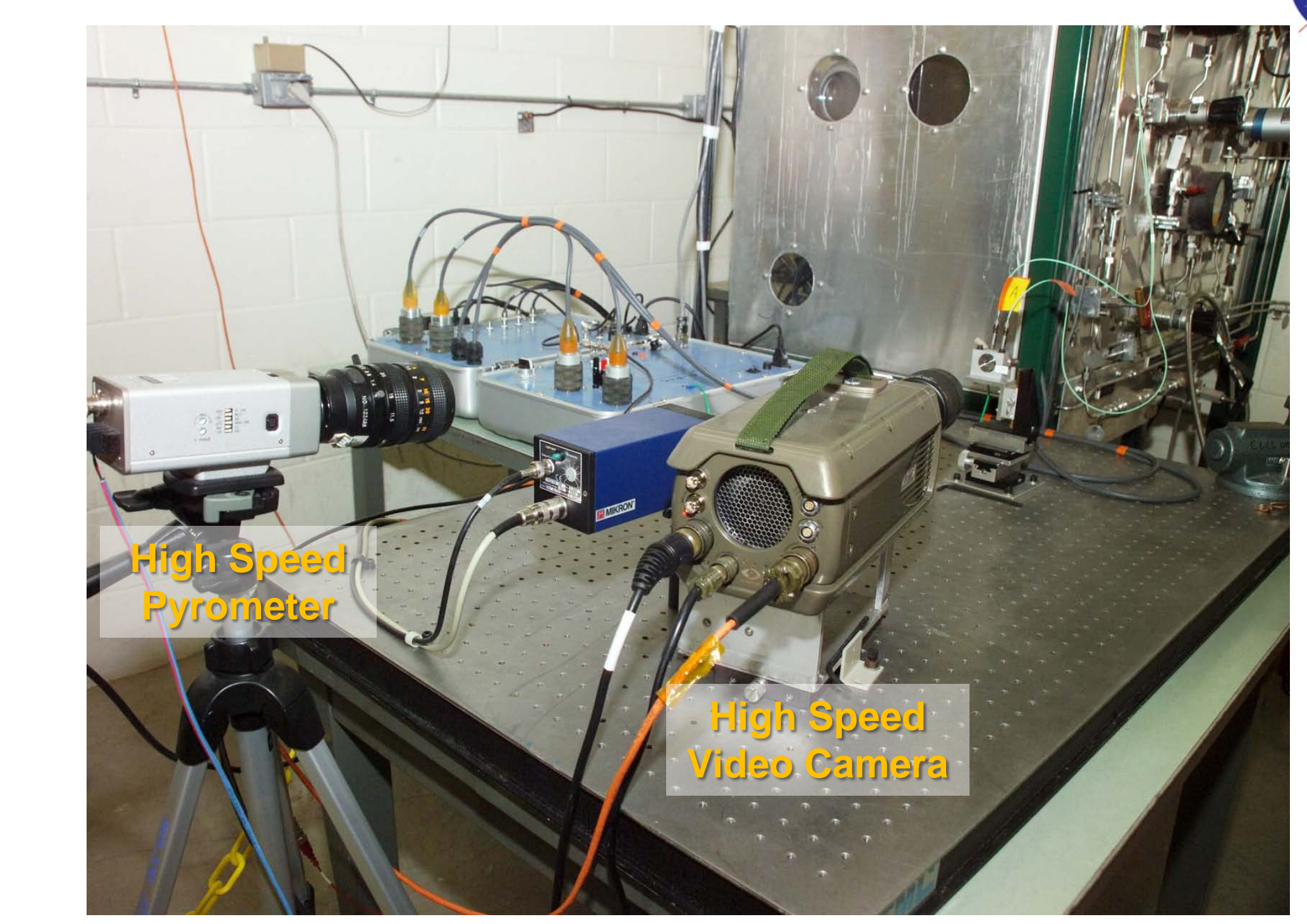

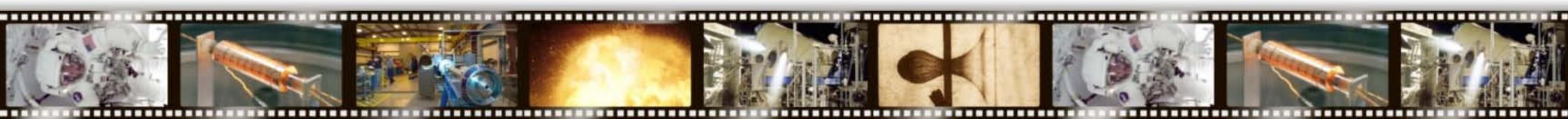




\section{Data Acquisition and Control Systems}

- Temperature was measured with an infrared pyrometer

- Response time of $6 \mu \mathrm{s}$

- Temperature range of $572{ }^{\circ} \mathrm{F}$ to $3632^{\circ} \mathrm{F}$

- Pressure in each NSI cavity was measured with miniature, high frequency, dynamic pressure sensors

- Firing circuitry provided variable timing with respect to firing one or both NSIs with a precision of $\pm 2 \mu \mathrm{s}$. The system provided firing current of 22 to 24 amps vs the normal NSI firing current of about 3 to 5 amps to minimize small variations in firing times 


\section{Data Acquisition and Control Systems}

- Data was acquired at 1 to $2 \mathrm{MHz}$ for either 20 or $40 \mathrm{~ms}$, depending on test requirements

- The data system is capable of $60 \mathrm{MHz}$

- Special attention was paid to eliminate ground loops or other interferences

- Effects on the booster cover simulator were recorded with high speed video at 20,000 frames per second

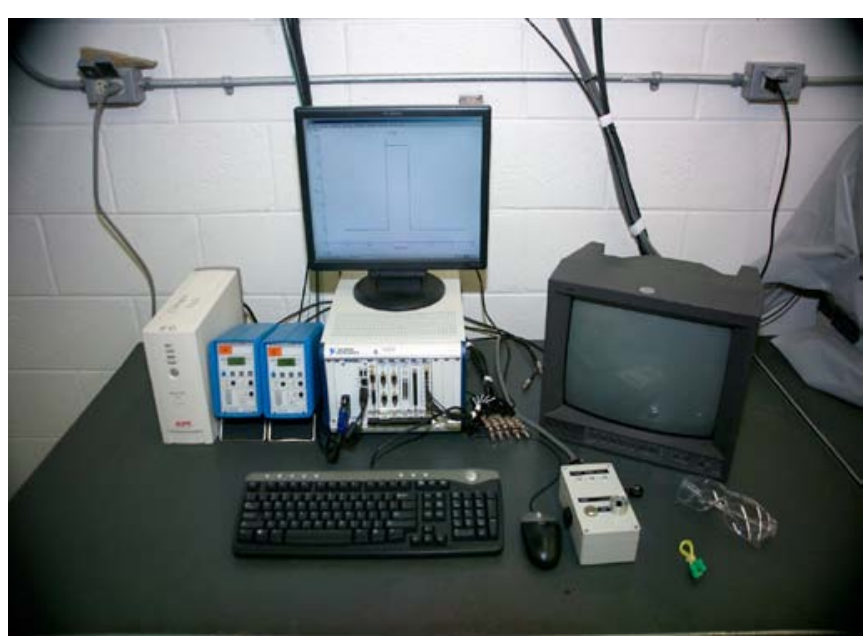

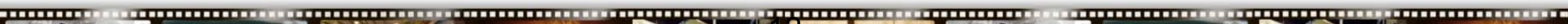




\section{Phase I Test Results}

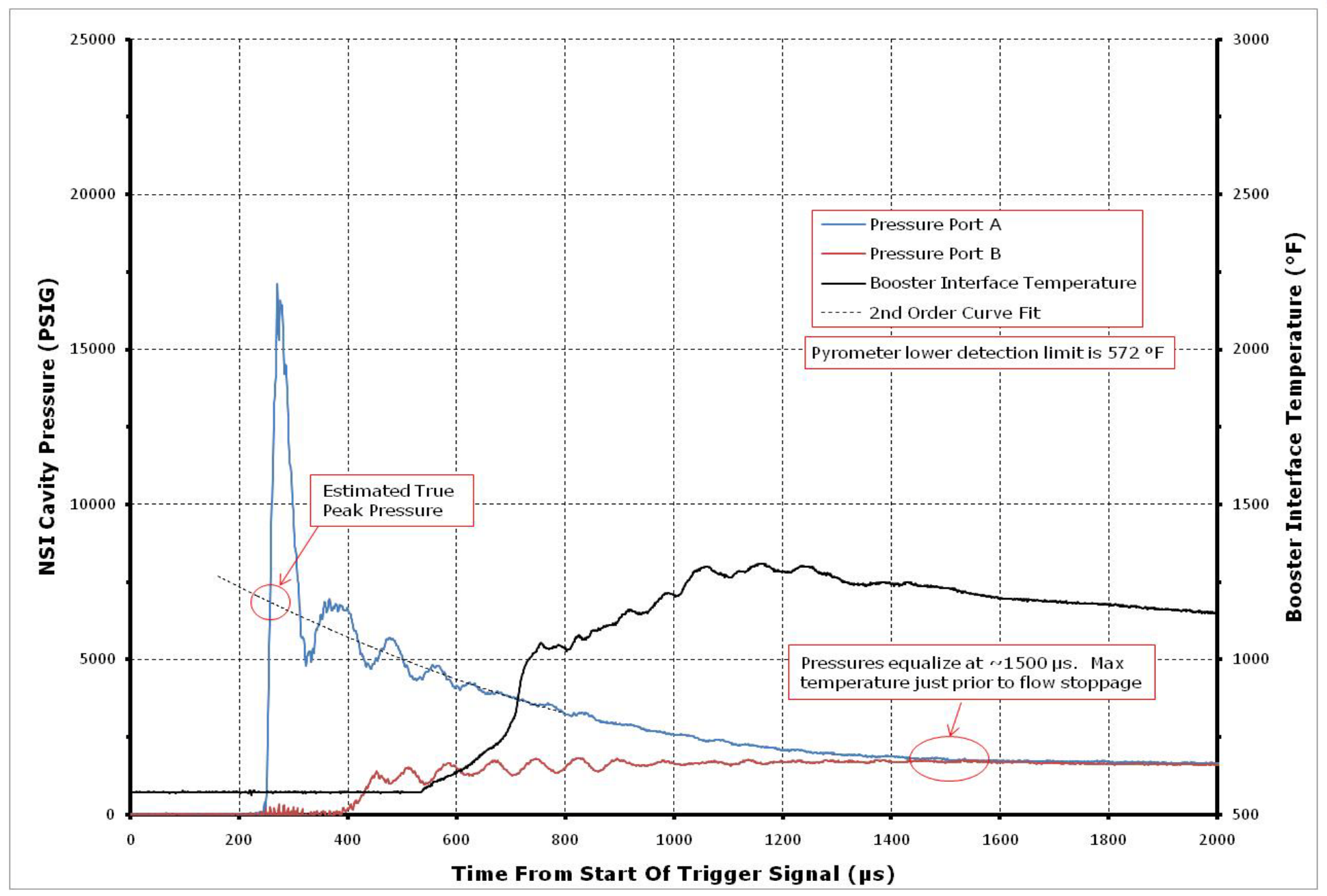

Typical Results From A Single NSI Firing In An AI Y-PCA

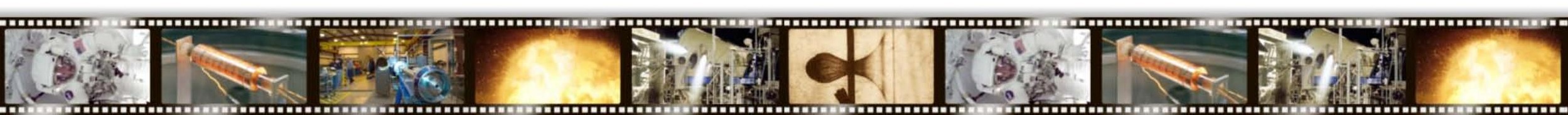




\section{Phase I Test Results}

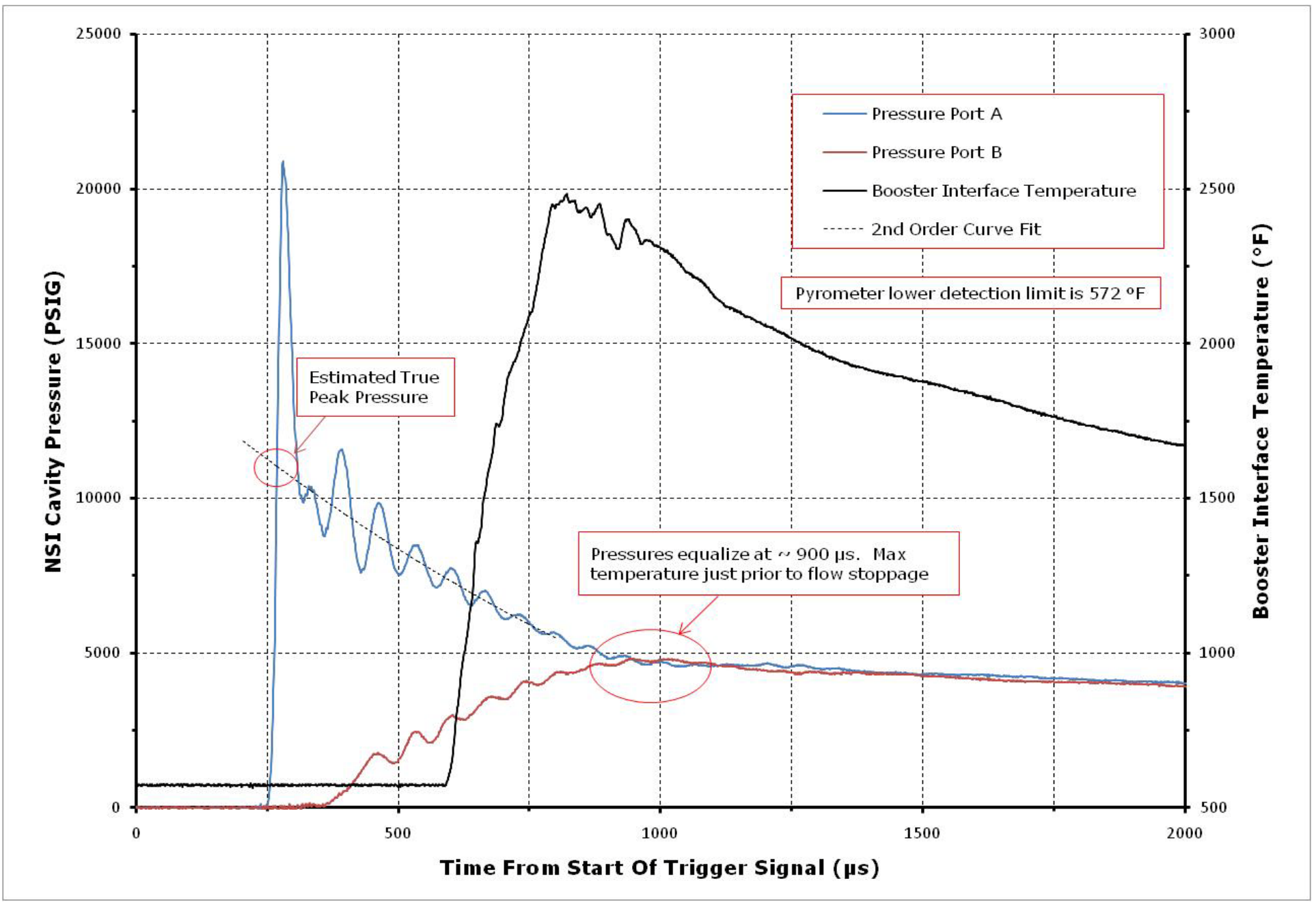

Typical Results From A Single NSI Firing In An SS V-PCA

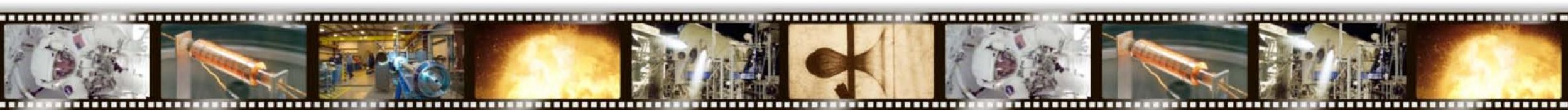




\section{Phase I Test Results}

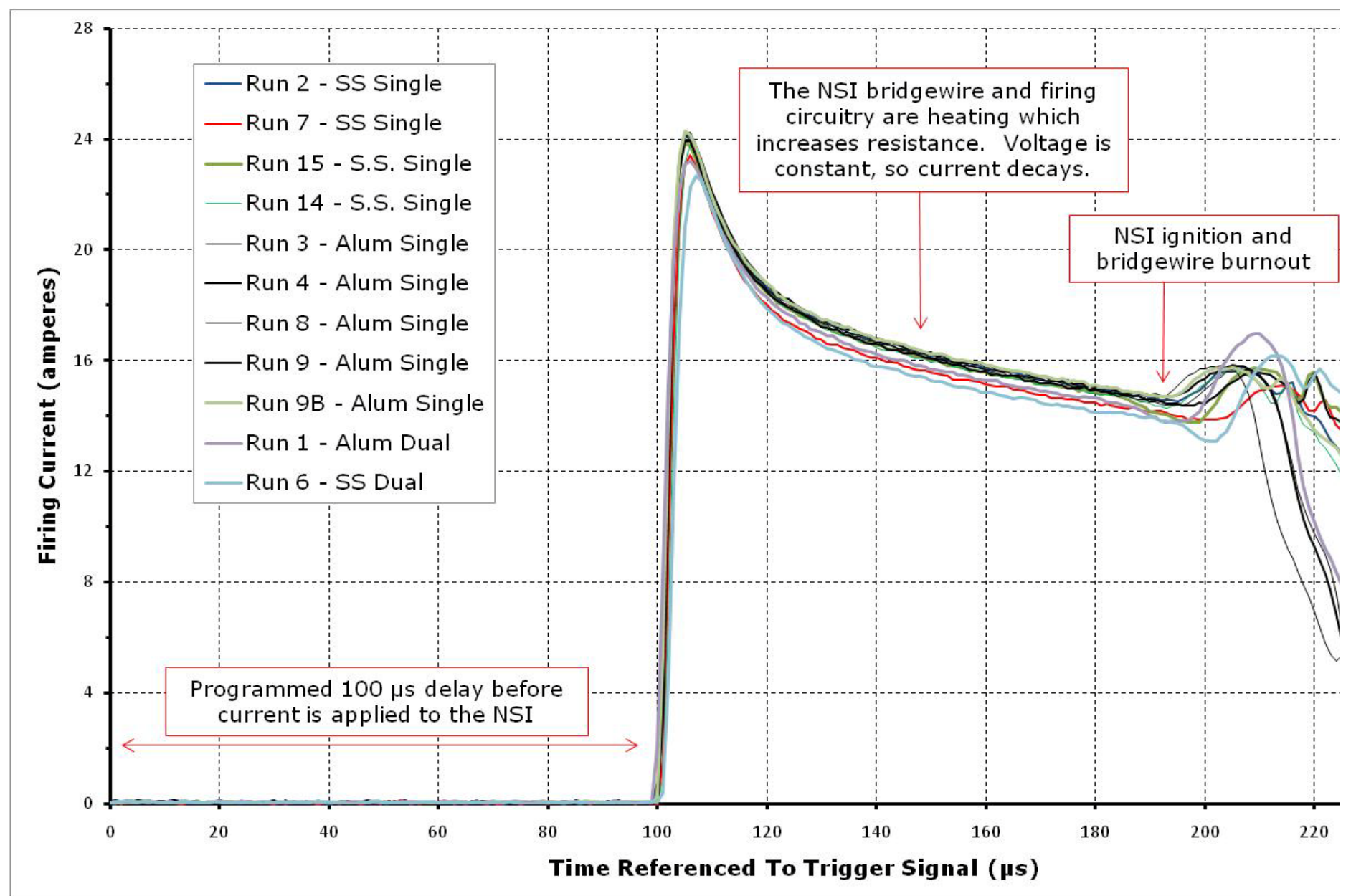

NSI Current vs Time for All Phase I Tests

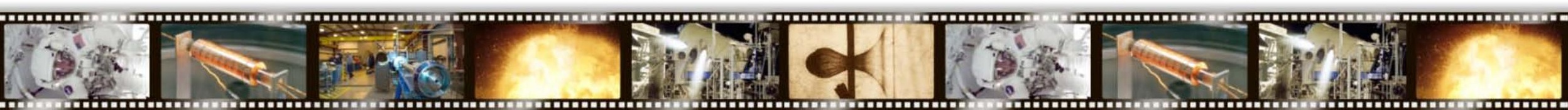


- The average maximum temperature was $2290^{\circ} \mathrm{F}$ for the SS VPCA, but only $1391^{\circ} \mathrm{F}$ for the legacy AI Y-PCA

- Each SS V-PCA test melted a hole through each booster cover simulator while the AI Y-PCA produced only very small, irregular cracks

- The SS V-PCAs produced much higher temperatures and pressures and were more likely to produce the desired penetration of the booster cover and booster charge ignition than the Al Y-PCAs

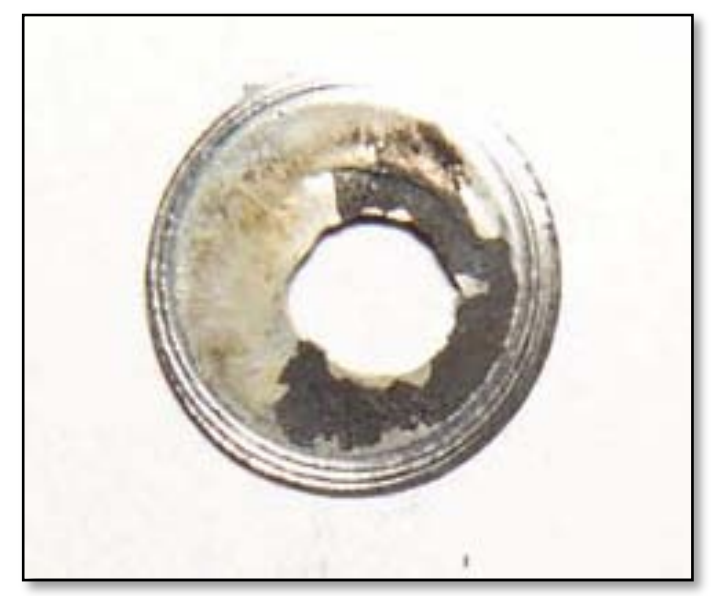

Booster Cover Simulator From Run \# 2 Shows A Hole Typical For A Single NSI, SS V-PCA Test 
- Phase IIA, SS V-PCAs with enlarged flow channels

- Evaluated the improvement in energy delivered to the booster interface

- Also tested dual, simultaneous NSI firings to determine if this failure mode is still possible if the flow channel is larger

- Phase IIB, SS V-PCAs with enlarged flow channels and staggered NSI firings (skews)

- Provide further investigation of staggered NSI firings at various area ratios 


\section{Phase IIA Test Results}

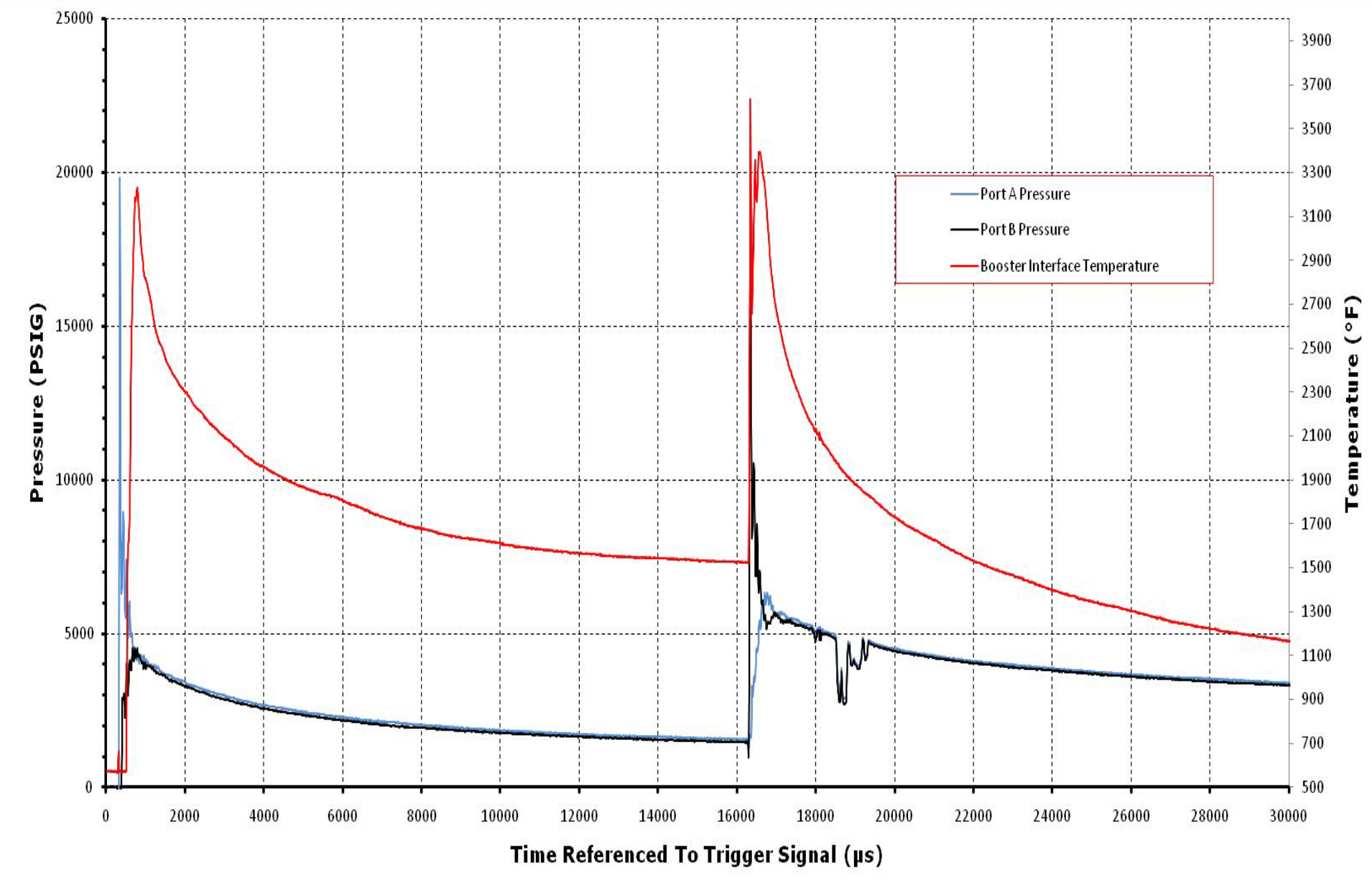

Phase IIA Run 4, SS V-PCA with .085 in. Diameter Flow Channels 


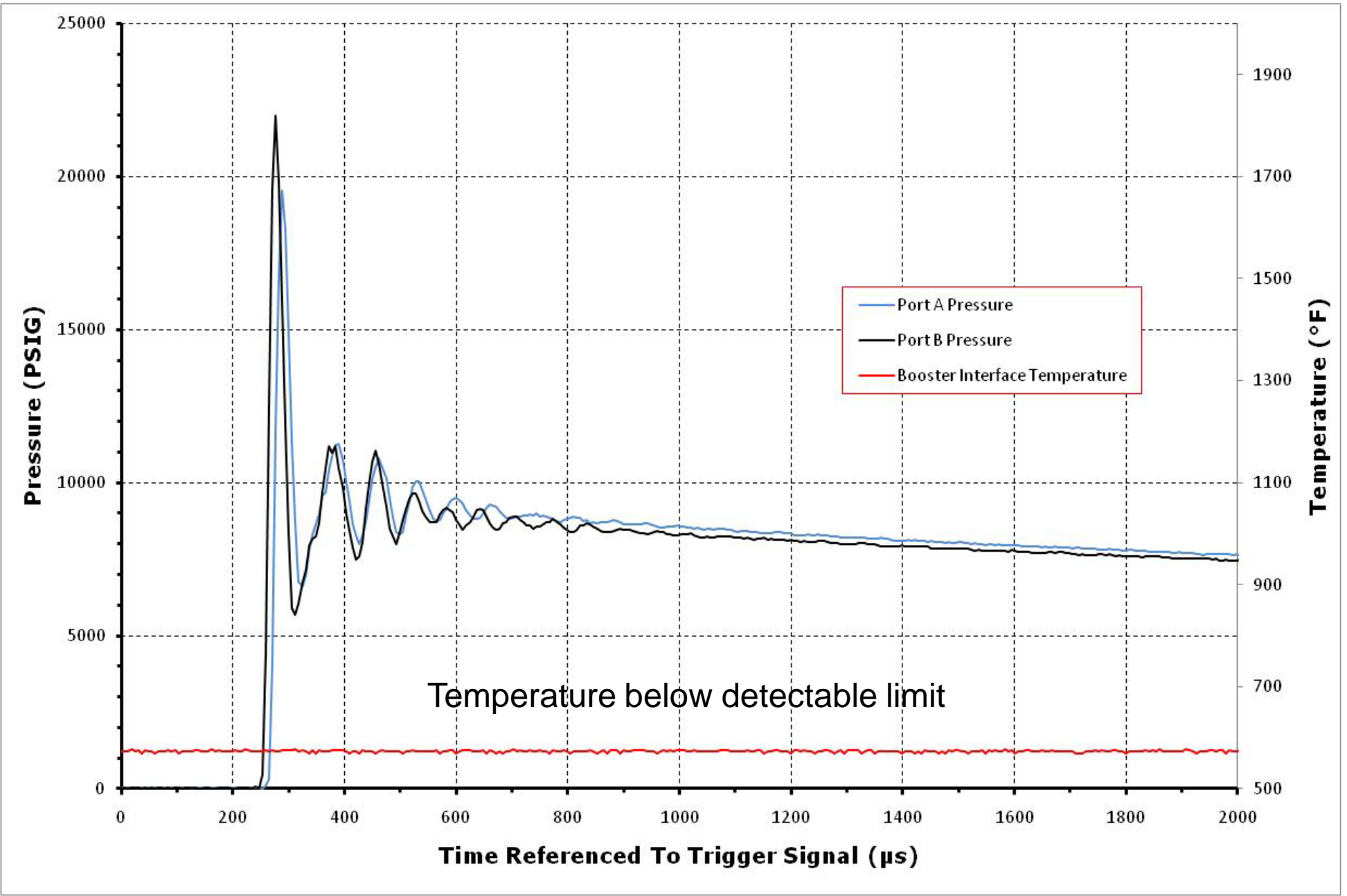

Phase IIA Run 1A, SS V-PCA With .120 in. Diameter Flow Channels (Dual, Simultaneous Firing) 
- One dual, simultaneous NSI firing with $4 x$ the nominal crosssectional area was performed

- Actual skew was $12 \mu \mathrm{s}$

- Failed to produce enough temperature rise at the booster propellant interface to register on the pyrometer $\left(572^{\circ} \mathrm{F}\right.$ or more)

- 1000 to $1100^{\circ} \mathrm{F}$ is the estimated requirement to ignite the booster propellant

- Three tests, one each with $1 x, 2 x$, and $4 x$ cross-sectional area and 16 ms skew, were performed and all produced a maximum temperature at the booster interface of $3400^{\circ} \mathrm{F}$

- Found that a short skew of $12 \mu \mathrm{s}$ or less may fail to ignite the booster propellant even with a large flow channel diameter and the more efficient SS V-PCA design

- The pyrovalve would fail to function 


\section{Phase IIA Results - Sample High Speed Videos}
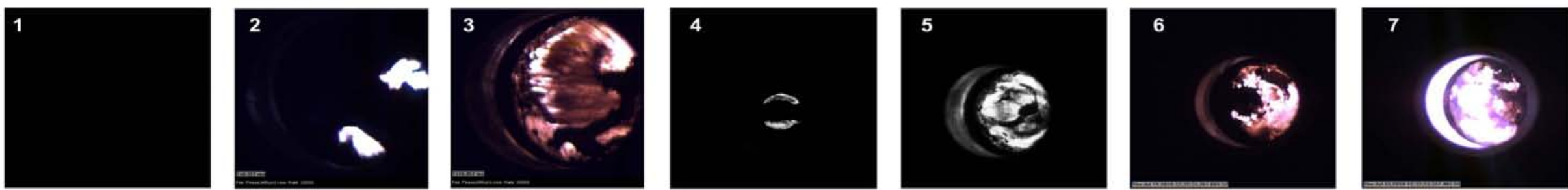

$\begin{array}{cccc}\begin{array}{c}\text { mage } \\ \text { No. }\end{array} & \text { Run No. } & \begin{array}{c}\text { Channel Dia } \\ \text { ( in.) }\end{array} & \begin{array}{c}\text { Skew } \\ \text { ( } \boldsymbol{\mu} \text { ) }\end{array} \\ 1 & 1 A & 0.120 & 12 \\ 2 & 2 \_1 & 0.120 & 16000 \\ 3 & 2 \_2 & 0.120 & 16000 \\ 4 & \text { 3A_1 } & 0.06 & 16000 \\ 5 & \text { 3A_2 } & 0.06 & 16000 \\ 6 & 4 \_1 & 0.085 & 16000 \\ 7 & 4 \_2 & 0.085 & 16000\end{array}$

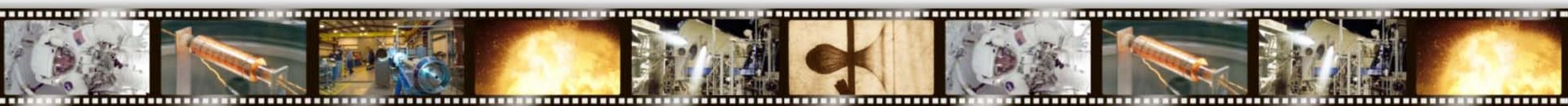




\section{Statistical Analysis and Results}

- Phase I

- Statement of problem was clearly developed

- Size of the test project was governed by resource considerations, but was sufficient to show clear and useful differences

- Phase II

- Designed to evaluate the relationship between firing skew and the cross-sectional area of the flow passages

- It was assumed that the following model would apply:

- $Y=\beta_{0}+\beta_{1}$ Skew $+\beta_{2}$ Area $+\beta_{12}$ Skew $\times$ Area $+\beta_{11}$ Skew $^{2}+\beta_{22}$ Area $^{2}$

- $\beta^{\prime}$ s are linear regression parameters fit using the data 


\section{Statistical Analysis and Results}

- Phase IIB Results

- Within the tested range of the two inputs studied, no-fires are entirely possible at low skews

- A no-fire at high skew and channel area suggests that channel area does not mitigate the risk of a no-fire, and a no-fire at more than $500 \mu \mathrm{s}$ could occur

- Temperatures increase with increasing skew, but are fairly insensitive to channel area

- Channel area affects pressure and increases variability of the time it takes to attain peak temperature 
- Simplified and detailed thermal analyses were performed by NASA Technical Fellow for Passive Thermal and his NESC Technical Discipline Team

- Convective heat transfer, by itself, does not account for the temperature rise and melting during this testing

- Deposition of liquid zirconia spray onto the booster cap results in more heat transfer than convection alone

- Zirconia deposition and the subsequent phase change from the liquid to solid state may assist in booster cap heating and subsequent melting, but does not produce booster cap temperatures in agreement with the booster cap transient temperature response observed during testing

- Larger quantities of zirconia deposition increase the propensity to melt and accelerate the temperature rise of the booster cap bottom 
- Detailed thermal analysis suggests that a hemispherical globule of zirconium-potassium perchlorate (ZPP) with a radius of $3.6 \times 10^{-3}$ in with a mass of $5.2 \times 10^{-3} \mathrm{mg}\left(1.14 \times 10^{-8} \mathrm{lbm}\right)$ can liberate sufficient energy to locally-melt through the booster cap

- Deposition of as little as 20 percent of the unburned ZPP ( $\sim 4.6 \mathrm{mg}$, or $\left.1 \times 10^{-5} \mathrm{lbm}\right)$ can liberate sufficient energy to melt the entire booster cap

- Subsequent two-dimensional axisymmetric thermal analysis shows that local melt-through can be accomplished with considerably less ZPP. From this, it is concluded that $<4.6 \mathrm{mg}$ ZPP burning in contact with the booster cap is sufficient to produce the observed response 
- Numerical simulations were accomplished by Craftech Industries, Inc.

- This numerical modeling effort, based on computational fluid dynamics, provided an improved understanding of the gas and particle flow physics within the V-PCA

- One of the primary issues explored by this test project, the dual, simultaneous NSI ignition anomaly, was explained as interaction of the shocks formed by the two NSIs and stagnation at the booster interface

- The stagnation condition and reflected waves appeared to reduce the amount of particles (hot burning) from reaching the booster membrane, causing the membrane temperature to be dramatically lower 
- Modeling of a modified V-PCA with additional chambers on either side of the flow channels

- Based on this modeling, one SS V-PCA was modified and tested

- Dual, simultaneous firing

- Object was to seek improved mitigation of the potential dual, simultaneous failure mode by observing better temperature results at the booster propellant interface 


\section{Accumulation of Particles Near the Booster Cap}

- The mass of particles in a zone near the booster cap is plotted below

- Figure on right shows location of mass integration zone

- Figure on left shows the time-varying total mass of particles in the integration zone normalized by the mass of particles contained within a single initiator charge

- After $100 \mathrm{~ms}$, the dual firing case shows half the amount of particles contained in the volume near the booster cap than the single firing case, despite having twice the amount of particles

- Due to the flow reversal, fewer particles are impacting the booster cap in the dual firing scenario

- Fundamental hypothesis for failure of simultaneous dual-firing still valid
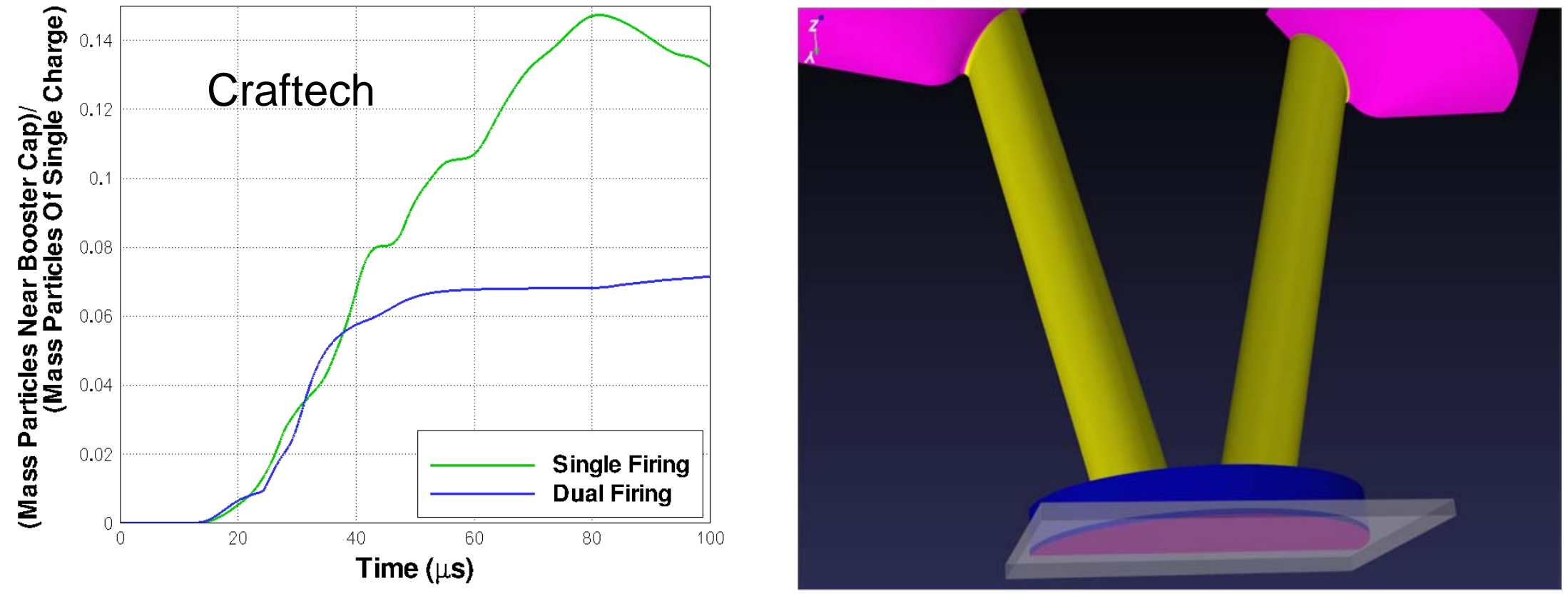

(10

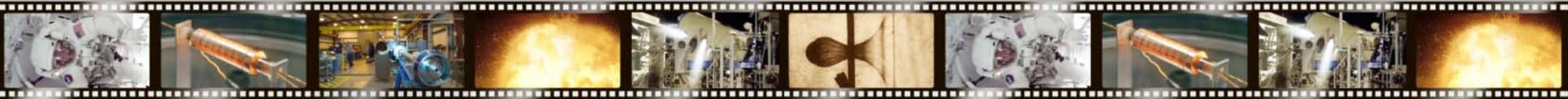




\section{Modified SS V-PCA Test}

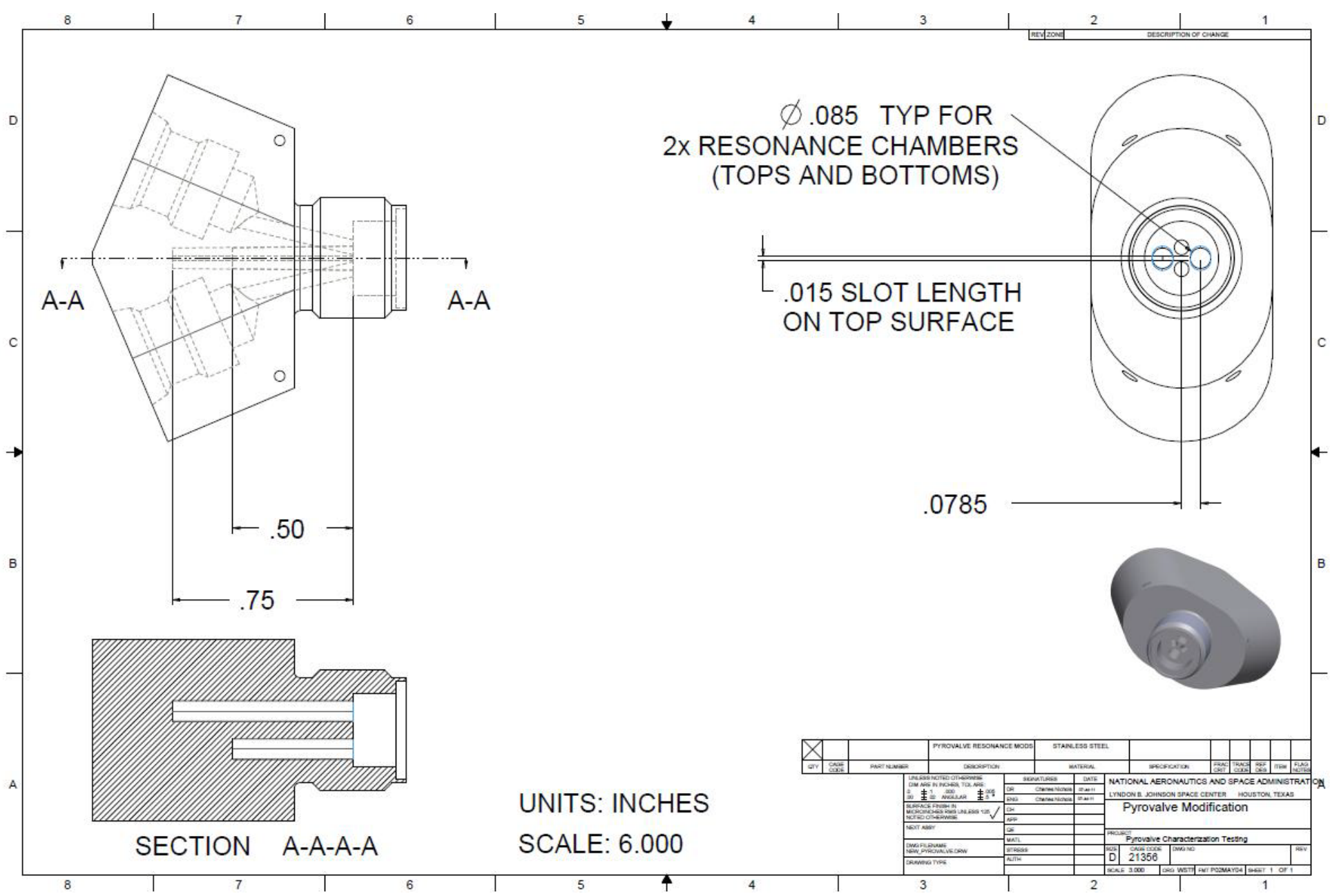

SS V-PCA Modified with Additional Chambers 


\section{Modified SS V-PCA Test}

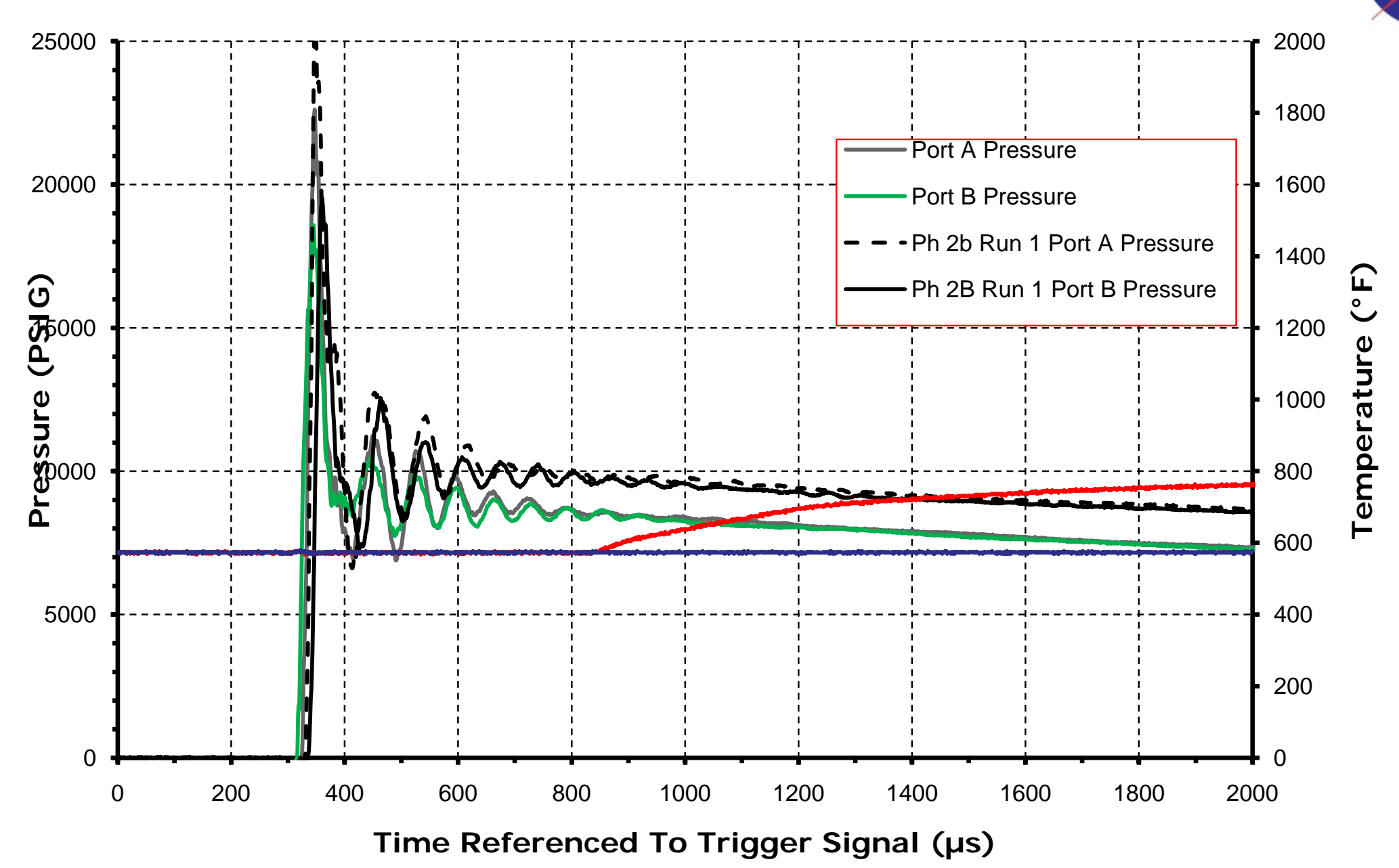

Resonant Chamber Test Compared to a Similar Dual,

Simultaneous Firing (Phase IIB, Run 1) 
- Pressure curves are very nearly identical, indicating very good correspondence between the two tests

- Although the modified SS V-PCA produced a higher temperature it is still below the threshold needed to ignite the booster powder reliably.

- Temperature rise with the modified SS V-PCA is very slow, indicating that heat transfer to the booster cover simulator is still restricted by flow stagnation

- Additional testing with larger volumes is needed 
1. The new SS design has a clear advantage over the heritage Al PCAs for single NSI firings

- SS V-PCA delivered about $600^{\circ} \mathrm{F}$ more energy to the booster propellant interface that the AI Y-PCA

- SS V-PCA delivered higher temperatures in approximately half the time; $776 \mu$ s average for the SS V-PCAs versus $1342 \mu$ s average for the Al Y-PCAs

- SS V-PCA produces a 38\% higher pressure on the average (as measured in the NSI cavity)

2. Dual, simultaneous (within $20 \mu \mathrm{s}$ ) firing of the redundant NSIs significantly reduces the performance of either PCA design to the point where it is doubtful the booster charge would be reliably ignited. The actual threshold for "no fire" may be higher than $20 \mu \mathrm{s}$ skew, but no failures were observed at $250 \mu$ s skew and higher 
3. Even with flow paths enlarged to 4 times the original cross-sectional area, test data indicates that dual, simultaneous (within $20 \mu \mathrm{s}$ ) firings of the redundant NSIs significantly reduces performance to the point where it is doubtful the booster charge would be reliably ignited

4. The assessment did not show consistent improvement with larger NSI flow channels, either with greater temperatures at the booster interface, or with a reduced probability of failure with dual, simultaneous NSI firings 


\section{Observations}

1. When the flow path diameter and the skew are high, they exert a considerable downward effect on peak pressure. The flow paths with cross-sectional areas 2 and 4 times greater than the original design produced lower pressures in the NSI cavity. The reduction was about 1600 psi and 2400 psi, respectively. This was not unexpected due to the obviously larger free volume with the enlarged flow paths.

2. Increasing the flow passage diameter from the original 0.060 -in. diameter to 0.125 -in. (4 times the original crosssectional area) lowers the maximum pressure inside of the PCA by about 2000 psi or about $21 \%$. 


\section{Observations}

3. A new and innovative temperature measurement method was developed and used for this assessment that is accurate to within $50^{\circ} \mathrm{F}$ over a range of $572{ }^{\circ} \mathrm{F}$ to $3632{ }^{\circ} \mathrm{F}$ and has an extremely rapid response time of $10 \mu \mathrm{s}$ or less. This may be valuable to other projects/programs.

4. SS PCA modeling was accomplished by Craftech. This not only provided a better understanding of the booster stagnation condition that results from a simultaneous NSI firing, but also suggested that additional chambers machined into the PCA might help preclude the stagnation condition and mitigate the anomaly. Fully exploring this mitigation was beyond the scope of this assessment 


\section{Recommendations}

1. Further explore, through testing, the merit of chambers of larger volume as recommended by Craftech to determine if this eliminates the dual, simultaneous restriction, which could reduce mission risk

2. Both AI Y-PCA design and SS V-PCA initiator firings should be skewed by at least $2 \mathrm{~ms}$ to eliminate the potential for a dual, simultaneous ignition of the initiators that could cause a pyrovalve malfunction. During testing, no anomalies were noted when command skew was greater than $250 \mu \mathrm{s}$, but the additional skew will provide margin for minor control system variability 


\section{Recommendations}

3. Programs should perform additional testing if closely sequenced pyrotechnic events make it desirable to reduce skew below $2 \mathrm{~ms}$

4. The SS V-PCA should be used on future NASA programs for improved margin unless weight factors dictate otherwise. This is believed to be especially important for manned spaceflight applications such as on Multipurpose Crew Vehicle (Orion) 
- Dual, simultaneous NSI test results with both PCA designs failed to produce temperatures above the detectable limit of the pyrometer $\left(572^{\circ} \mathrm{F}\right)$

- 1000 to $1100^{\circ} \mathrm{F}$ is estimated to be the minimum temperature required to ignite the booster propellant

- In both tests, the NSI hot gases and particles produced only minimal damage to the booster cover simulator

- This is a credible failure mode with either PCA design
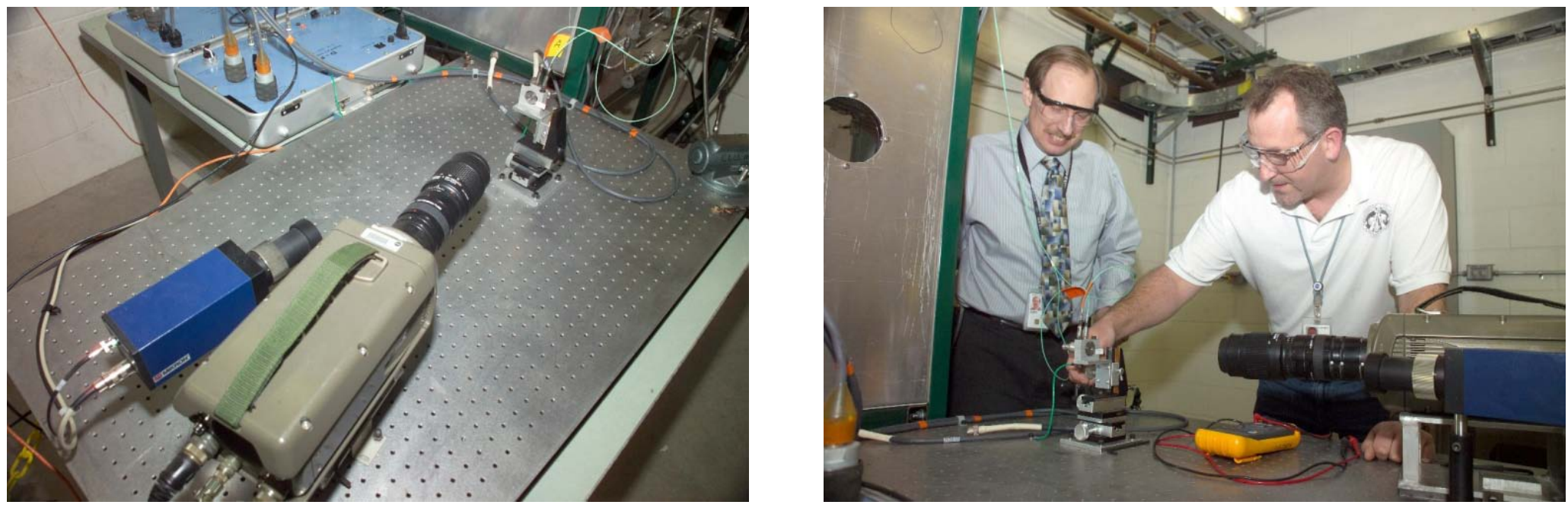
Heritage Aluminum Design With "Y"-Shaped Flow Channel Versus MSL Stainless Steel Design with "V"-shaped Flow Channel

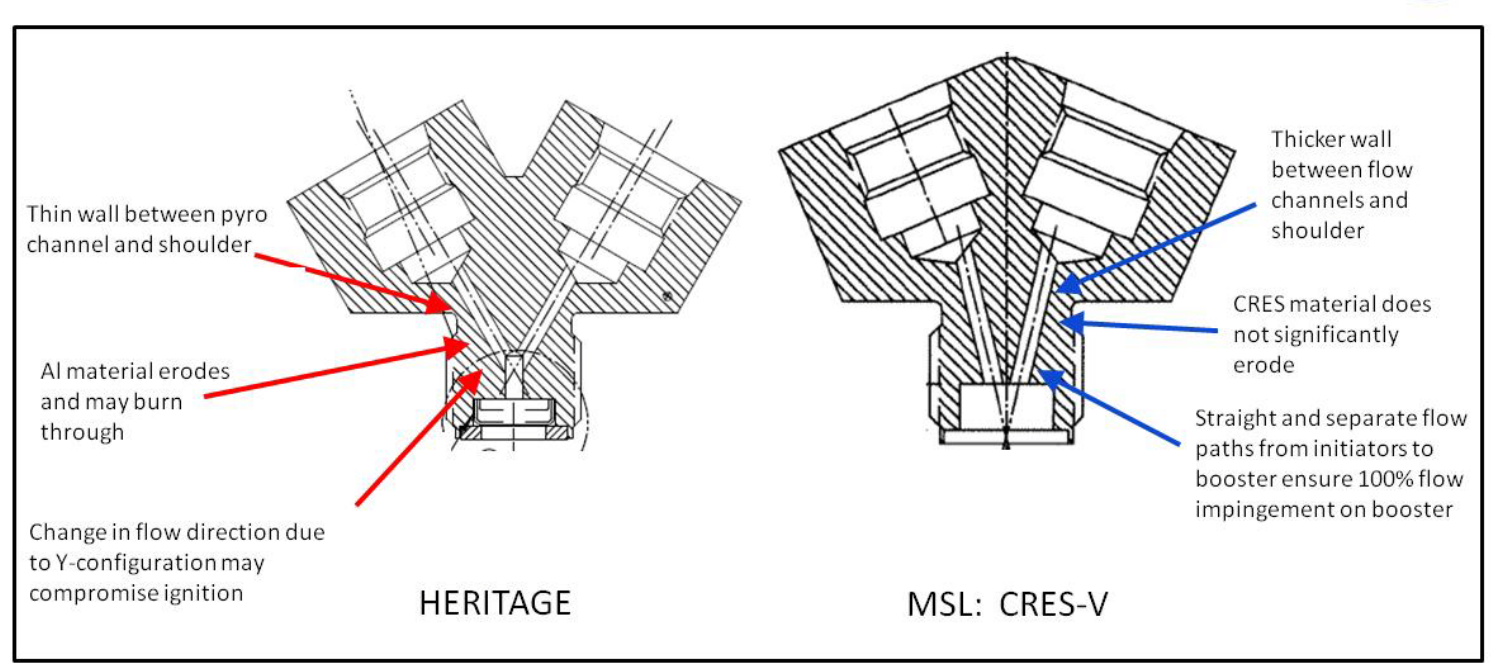

Posttest, Sectioned Stainless

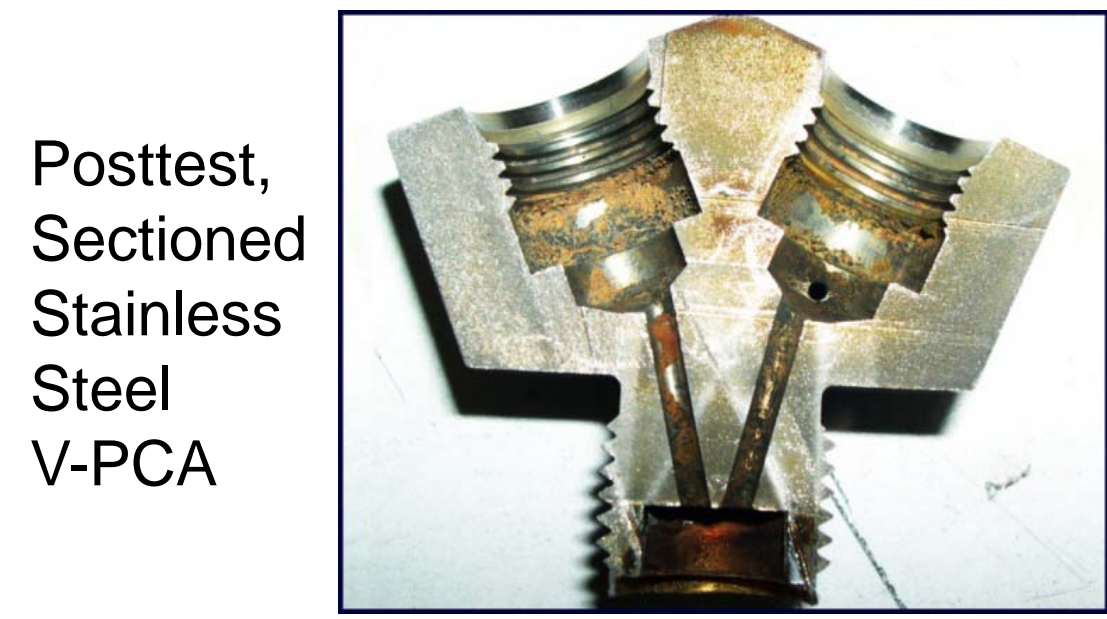

Posttest, Sectioned Aluminum Y-PCA Steel

V-PCA

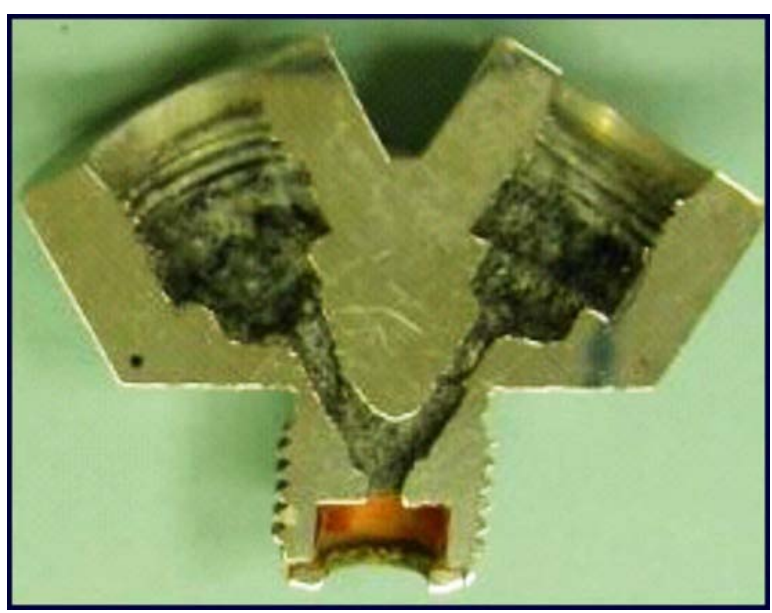


Phase IIB - Post-Test Images of The Booster Cover Simulators, Sapphire Windows, and Sealing Rings

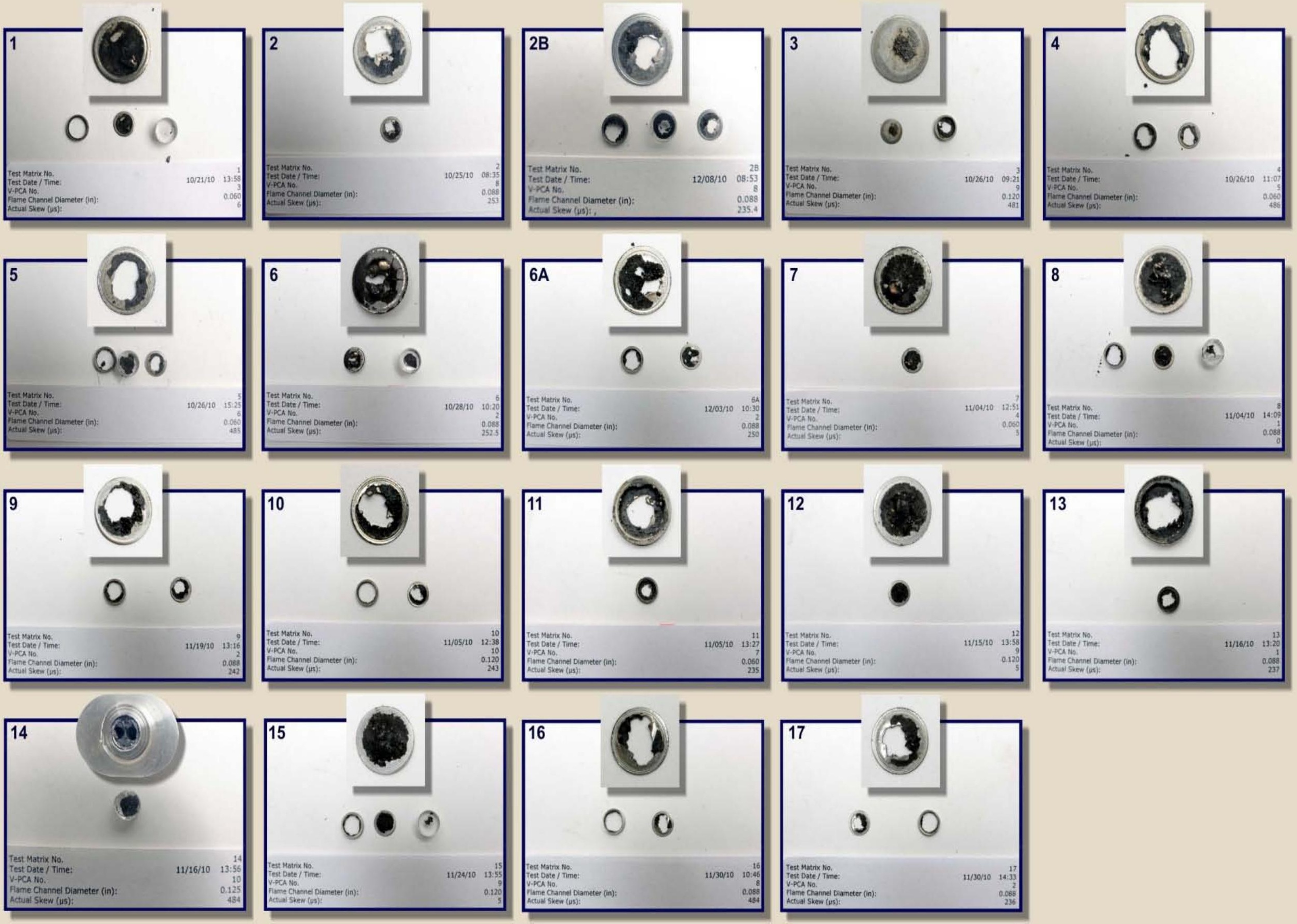


- Combination of L/D and Skew testing into one experiment makes it reasonable

- For each factor level combination, use a single PCA

- Block one day, running a set number of trials each day; run test over two days

- Randomize within blocks, holding all other sources of variability as constant as possible

Phase IIB Test Matrix As Performed

\begin{tabular}{|c|c|c|c|c|c|c|}
\hline Phase & Run & Date & $\begin{array}{c}\text { Channel } \\
\text { Diameter } \\
(\mathrm{in})\end{array}$ & $\begin{array}{c}\text { Channel } \\
\text { Cross- } \\
\text { section }\end{array}$ & $\begin{array}{c}\text { Nominal } \\
\text { Skew } \\
(\mu \mathrm{s})\end{array}$ & $\begin{array}{c}\text { Actual } \\
\text { Skew } \\
(\mu \mathrm{s})\end{array}$ \\
\hline 2B & 1 & $10 / 21 / 10$ & 0.060 & $1 \mathrm{X}$ & 5 & 6 \\
\hline 2B & 3 & $10 / 26 / 10$ & 0.125 & $4 \mathrm{X}$ & 500 & 481 \\
\hline 2B & 4 & $10 / 26 / 10$ & 0.060 & $1 \mathrm{X}$ & 500 & 486 \\
\hline 2B & 5 & $10 / 26 / 10$ & 0.060 & $1 \mathrm{X}$ & 500 & 485 \\
\hline 2B & 7 & $11 / 04 / 10$ & 0.060 & $1 \mathrm{X}$ & 5 & 5 \\
\hline 2B & 8 & $11 / 04 / 10$ & 0.088 & $2 \mathrm{X}$ & 5 & 0 \\
\hline 2B & 10 & $11 / 05 / 10$ & 0.125 & $4 \mathrm{X}$ & 250 & 243 \\
\hline 2B & 11 & $11 / 05 / 10$ & 0.060 & $1 \mathrm{X}$ & 250 & 235 \\
\hline 2B & 12 & $11 / 15 / 10$ & 0.125 & $4 \mathrm{X}$ & 5 & 5 \\
\hline 2B & 13 & $11 / 16 / 10$ & 0.088 & $2 \mathrm{X}$ & 250 & 237 \\
\hline 2B & 14 & $11 / 16 / 10$ & 0.125 & $4 \mathrm{X}$ & 500 & 484 \\
\hline 2B & 9 & $11 / 19 / 10$ & 0.088 & $2 \mathrm{X}$ & 250 & 242 \\
\hline 2B & 15 & $11 / 24 / 10$ & 0.125 & $4 \mathrm{X}$ & 5 & 5 \\
\hline 2B & 16 & $11 / 30 / 10$ & 0.088 & $2 \mathrm{X}$ & 500 & 484 \\
\hline 2B & 17 & $11 / 30 / 10$ & 0.088 & $2 \mathrm{X}$ & 250 & 236 \\
\hline 2B & $6 \mathrm{~A}$ & $12 / 03 / 10$ & 0.088 & $2 \mathrm{X}$ & 250 & 250 \\
\hline 2B & $2 \mathrm{~B}$ & $12 / 08 / 10$ & 0.088 & $2 \mathrm{X}$ & 250 & 236 \\
\hline
\end{tabular}



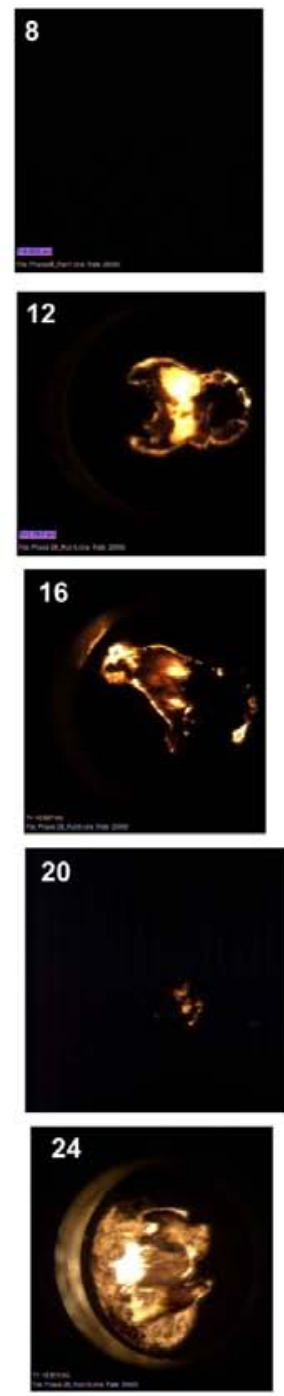
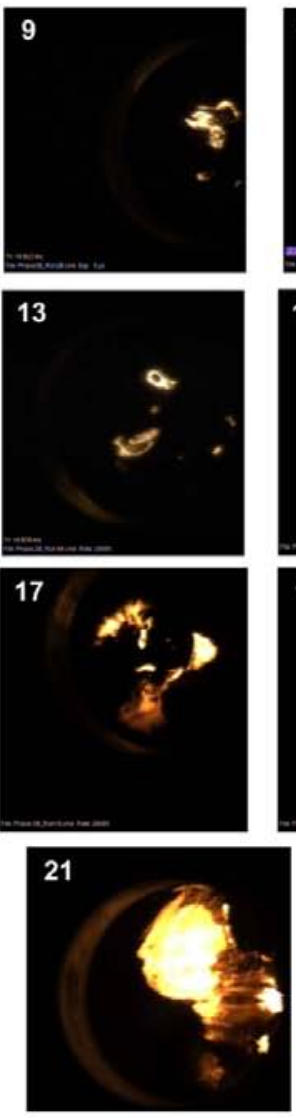

25
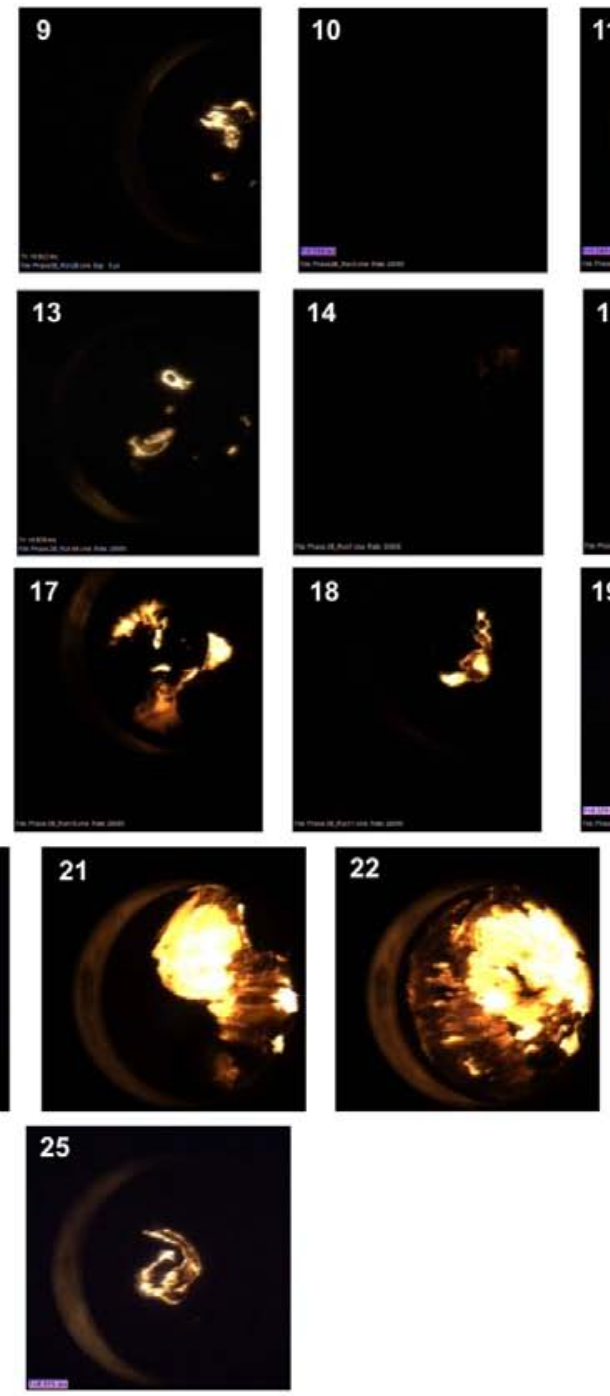
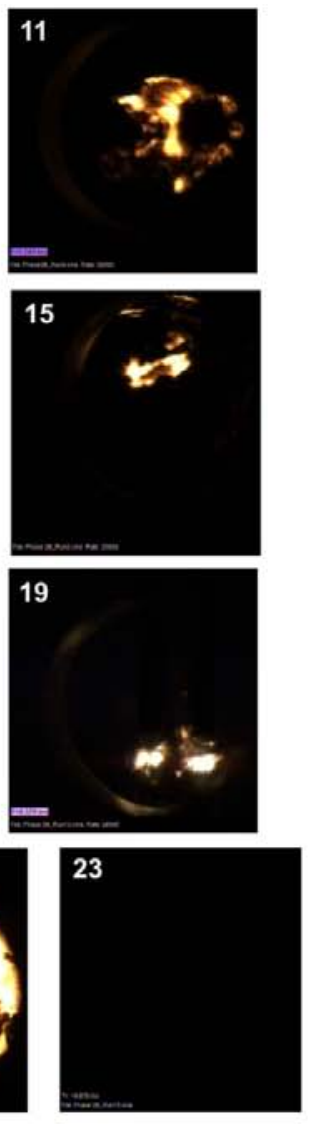

\section{I mage} No.

8

9

10

11

12

13

14

15

16

17

18

19

20

21

22

23

24

25
Channel Dia Skew (in.) ( $\mu s)$

$0.06 \quad 6$

$0.085 \quad 236$

$0.120 \quad 481$

$0.06 \quad 486$

$0.06 \quad 485$

$0.085 \quad 250$

0.06

0.085

0.085

0.120

0.06

0.120

0.085

0.120

0.120

0.120

0.085

0.085
5

0

242

243

235

5

237

484

484

5

484

236 


\section{Phase I Test Results}
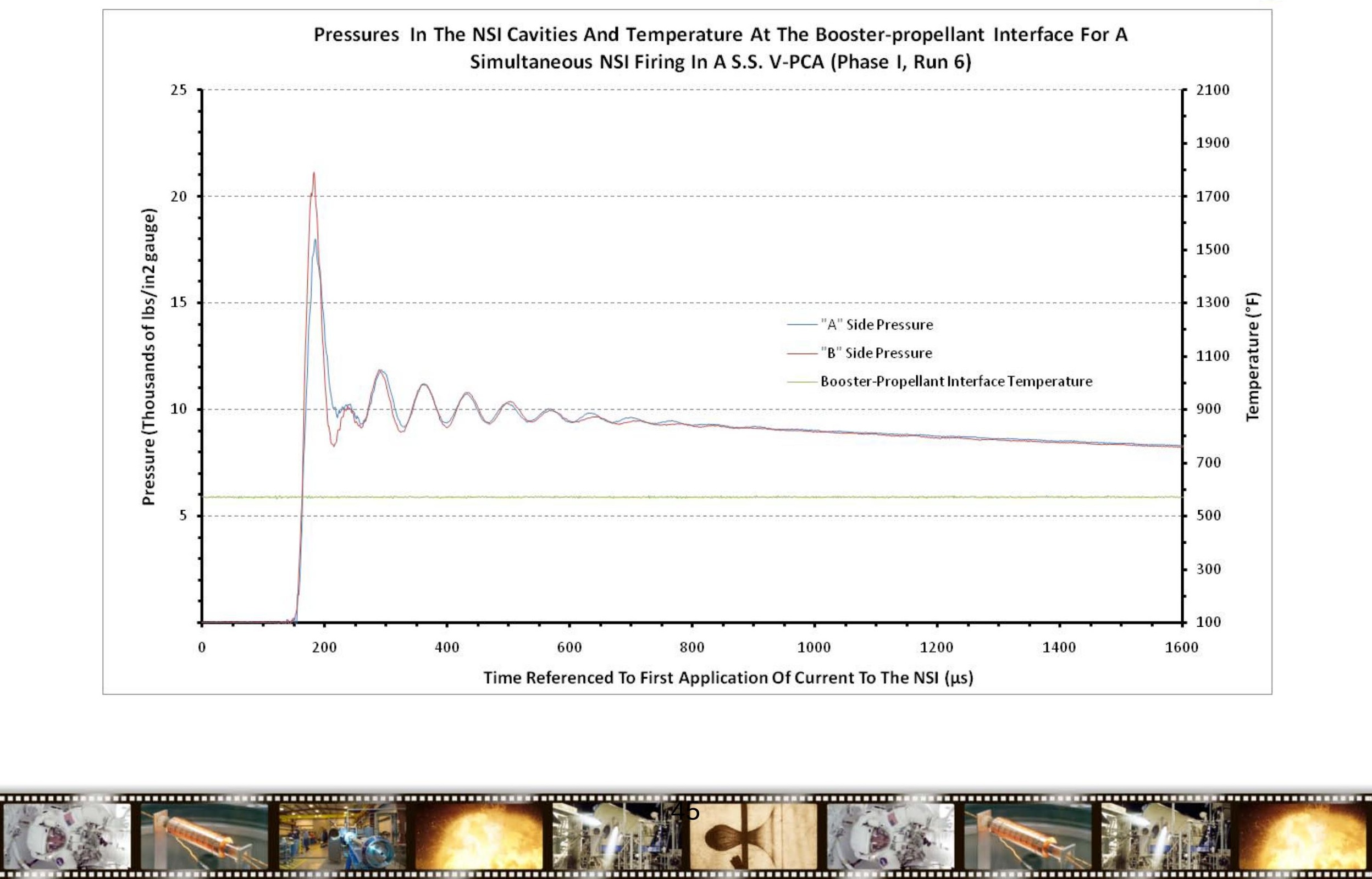


\section{Team Membership}

\begin{tabular}{|c|c|c|}
\hline Name & Discipline & Organization \\
\hline \multicolumn{3}{|l|}{ Core Team } \\
\hline $\begin{array}{l}\text { Roberto } \\
\text { Garcia }\end{array}$ & NESC Team Lead & MSFC \\
\hline $\begin{array}{l}\text { Regor } \\
\text { Saulsberry }\end{array}$ & NESC Assessment Lead & WSTF \\
\hline Stephen McDougle & Deputy Assessment Lead & MEI Tech, WSTF \\
\hline Tony Carden & Electrical Engineer & ERC, WSTF \\
\hline Ken Johnson & Statistics & MSFC \\
\hline Loutricia Johnson & Program Analyst & LaRC \\
\hline Adam Pender & Propulsion Systems & Lockheed Martin \\
\hline Asia Quince & Pyrotechnics & JSC \\
\hline Bill Sipes & Pyrotechnics Devices & WSTF \\
\hline Sandra Verba & Sr. Prog Mgr Aerospace/Pyrovalves & Conax Florida Corporation \\
\hline \multicolumn{3}{|l|}{ Consultants } \\
\hline Saverio D'Agostino & Materials and Processes & JPL \\
\hline Carl Guernsey & MSL Prop System & JPL \\
\hline Michael Hagopian & Propulsion Systems Components & GSFC \\
\hline Masashi Mizukami & MSL Prop System & JPL \\
\hline Troy Rayner & Senior Propulsion Engineer & Lockheed Martin \\
\hline Steve Rickman & Thermal Analysis Technical Fellow & JSC \\
\hline Robert Sadenwater & $\begin{array}{l}\text { Aerospace Engineering Supervisor - } \\
\text { Pyrovalves }\end{array}$ & Conax Florida Corporation \\
\hline Keith Van Tassel & Pyrotechnic Systems & JSC \\
\hline Richard Webster & Pyrotechnic Systems & JPL \\
\hline Stephen Woods & Propellant Physicist & Jacobs WSTF \\
\hline Zachary Zenz & Pyrovalve Design Engineer & Conax Florida Corporation \\
\hline \multicolumn{3}{|c|}{ Administrative Support } \\
\hline Tina Dunn-Pittman & Project Coordinator & LaRC/ATK \\
\hline Donna Gilchrist & Planning and Control Analyst & LaRC/ATK \\
\hline Erin Moran & Technical Writer & LaRC/ATK \\
\hline
\end{tabular}

Core Team

Garci

Rego

Saulsberry

Deputy Assessment Lead

MEI Tech, WSTF

Ken Johnson

Loutricia Johnson

Program Analyst

Adam Pender

Propulsion Systems

Pyrotechnics Devices

WSTF

Bill Sipes

Sandra Verba

Materials and Processes

MSL Prop System

Carl Guernsey

Propulsion Systems Components

Troy Rayner

Senior Propulsion Enginee

Thermal Analysis Technical Fellow

Aerospace Engineering Supervisor -

Pyrovalves

Pyrotechnic System

Pyrotechnic Systems

Propellant Physicist

Jacobs WSTF

Zachary Zenz

LaRC/ATK 
- Supporting Data From Earlier Testing

- Overall Legacy AI Y-PCA body of historic data, including NESC, MSL, LM, MRO data (20 tests)

- $518 \mu$ s to ignition, $475 \mu$ s standard deviation

- Time referenced to start of NSI pressure rise

- MSL SS V-PCA, 12 Tests

- $301 \mu$ s to booster ignition, $111 \mu$ s standard deviation 
- A statistical design of experiments approach was used to plan the tests

- Effective use of test hardware

- Random test order to reduce effects of uncontrolled variables

- Some compromises had to be made for operational efficiency and problems with the sapphire windows 


\section{Understanding How the Device Works}

- What are the mechanisms for potential energy loss?

- Thermal paths such as phase change of the aluminum

- Mechanical paths such as deformation of Y-PCA body materials might cause permanent volume increases and associated heating of the interior of the Y-PCA body.

- Kinetic Energy and Flow

- Byproducts of Y-PCA materials participating with the ZPP burn and substantially reducing the number of product moles

- Incomplete burning of the ZPP in the NSI

- Energy balance analyses performed at WSTF

- Gordon-McBride chemical reaction computer code

- Subject of another paper 